\title{
Photonic Crystals for Plasmonic Photocatalysis
}

\author{
Tharishinny Raja-Mogan ${ }^{1,2}$, Bunsho Ohtani ${ }^{1,2}$ and Ewa Kowalska ${ }^{1,2, *(1)}$ \\ 1 Graduate School of Environmental Science, Hokkaido University, Sapporo 060-0810, Japan; \\ rajamogan.t@cat.hokudai.ac.jp (T.R.-M.); ohtani@cat.hokudai.ac.jp (B.O.) \\ 2 Institute for Catalysis (ICAT), Hokkaido University, Sapporo 001-0021, Japan \\ * Correspondence: kowalska@cat.hokudai.ac.jp
}

Received: 6 July 2020; Accepted: 21 July 2020; Published: 23 July 2020

\begin{abstract}
Noble metal (NM)-modified wide-bandgap semiconductors with activity under visible light (Vis) irradiation, due to localized surface plasmon resonance (LSPR), known as plasmonic photocatalysts, have been intensively studied over the last few years. Despite the novelty of the topic, a large number of reports have already been published, discussing the optimal properties, synthesis methods and mechanism clarification. It has been proposed that both efficient light harvesting and charge carriers' migration are detrimental for high and stable activity under Vis irradiation. Accordingly, photonic crystals (PCs) with photonic bandgap (PBG) and slow photon effects seem to be highly attractive for efficient use of incident photons. Therefore, the study on PCs-based plasmonic photocatalysts has been conducted, mainly on titania inverse opal (IO) modified with nanoparticles (NPs) of NM. Although, the research is quite new and only several reports have been published, it might be concluded that the matching between LSPR and PBG (especially at red edge) by tuning of NMNPs size and IO-void diameter, respectively, is the most crucial for the photocatalytic activity.
\end{abstract}

Keywords: light harvesting; localized surface plasmon resonance; LSPR; photonic bandgap; PBG; photonic crystal; plasmonic photocatalysis; slow photons; titania inverse opal; vis-responsive photocatalysts

\section{Introduction}

Solar photocatalysis has been considered as one of the possible solutions for main crises facing humanity, i.e., energy, environment and water. It is believed that solar energy in the presence of photocatalyst might efficiently: (i) be converted into electricity/fuel, (ii) decompose chemical and microbiological pollutants, and (iii) purify water [1,2]. Accordingly, a large number of studies on development of efficient and stable photocatalysts have already been performed. Among various photocatalytic materials, wide-bandgap semiconductors are still the most widely investigated despite low harvesting efficiently of solar energy. It should be pointed out that though the wide bandgap is detrimental for light harvesting (absorption edge near $400 \mathrm{~nm}$ ), it usually results in high reactivity in both oxidation and reduction reactions under UV, especially for oxide semiconductors, since valence band (VB) and conduction band (CB) are highly positive and negative, respectively [3-5]. However, it should be also remembered that all semiconductors suffer from charge carriers' recombination either in the bulk or on the surface [6]. Therefore, wide-bandgap semiconductors have been modified with various elements/compounds, and thus obtained materials exhibit much higher quantum yields of photocatalytic reactions [7]. For example, nanoparticles (NPs) of noble metals (NMs) have been used to inhibit charge carriers' recombination, as NMs work as an electron sink (higher work function than electron affinity of oxides). Kraeutler and Bard were probably the first who proved this more than 40 years ago [8]. Since then various studies on photocatalytic activity enhancement by semiconductor modification with NM have been performed, including optimization of the properties of NM/semiconductor and the mechanism clarifications [9-12]. Additionally, some complexes and 
clusters of NMs have shown Vis absorption, and thus semiconductors have been modified with them to obtain Vis response, e.g., $\mathrm{PtCl}_{4}[13]$ and $\left[\mathrm{Pt}_{3}(\mathrm{CO})_{6}\right]_{6}{ }^{2-}$ clusters [14]. More than a decade ago another property of NMNPs have been used to activate wide-bandgap semiconductors towards Vis response, i.e., localized surface plasmon resonance (LSPR) [15]. Since then, many studies have been reported, and the photocatalysts containing NM deposits and being active under Vis irradiation have been named as plasmonic photocatalysts. Although the research on plasmonic photocatalysis is quite new, there are many reports on their synthesis, properties, applications, and mechanism dispute, including review papers and book chapters [16-19], and journal special issues [20,21], as shortly presented in the next sections. However, this review is not summarizing/discussing all these reports on plasmonic photocatalysis but focuses on the novel topic using semiconductors in the form of photonic crystals (PCs) as a support for NMNPs. It has been expected that such photocatalysts should possess high photocatalytic activity due to enhanced light harvesting inside PCs. The synthesis methods, properties and some application examples of PCs-based plasmonic photocatalysts are presented further.

\section{Plasmonic Photocatalysis}

Although, it is unknown by whom and when the term of "plasmonic photocatalysis" has been created, it is quite convenient to distinguish the activity of NM-modified wide-bandgap semiconductors under Vis irradiation from their well-known activity under UV. The activity under Vis irradiation originates from the properties of NMs, i.e., LSPR at Vis-NIR range of solar spectrum, in contrast to the activity under $\mathrm{UV}$, where semiconductor is mainly responsible for the photocatalytic performance. LSPR is the result of the confinement of a surface plasmon in an NP of the size similar or smaller than the wavelength of light used to excite the plasmon, i.e., when an NP is irradiated, the oscillating electric field causes the conduction electrons to oscillate coherently. The majority of studies on plasmonic photocatalysis have been performed on titania (titanium(IV) oxide, titanium dioxide), but also other semiconductors have been tested, e.g., $\mathrm{CeO}_{2}$ [22], $\mathrm{Fe}_{2} \mathrm{O}_{3}$ [23], $\mathrm{ZnO}$ [24], $\mathrm{KNbO}_{3}$ [25], g- $\mathrm{C}_{3} \mathrm{~N}_{4}$ [26], $\mathrm{AgCl}$ [27], $\mathrm{Ag}_{2} \mathrm{MoO}_{4} / \mathrm{AgBr}$ [28], and $\mathrm{ZrO}_{2} @ \mathrm{CoFe}_{2} \mathrm{O}_{4}$ [29]. Although plasmonic properties of NMs were found more than a century ago, and commercially used in many fields (e.g., medicine, SERS, and optical data storage), the examination of their potential for photocatalysis under Vis irradiation is quite new. Despite their novelty, many studies have already been conducted, including the improvement of the photocatalytic activity and stability as well as the explanation of the mechanism under visible light. Although the application of LSPR in the photocatalysis started at the beginning of this century, it was used only for the characterization of gold deposits on titania, i.e., the formation, properties and the stability under UV irradiation [30]. Next, $\mathrm{Au} / \mathrm{TiO}_{2}$ was used as Vis-responsive photocatalyst for generation of photocurrent [15] and oxidative degradation of organic compounds, such as methyl tert-butyl ether [31] and 2-propanol [32]. It should be mentioned that the direct proof confirming that LSPR is responsible for visible-light activity has been shown by action spectrum (AS) analyses [15,32], i.e., action spectra correlate with respective absorption spectra (the highest activity at max LSPR). Unfortunately, the mechanism under visible-light irradiation has not been agreed till now, and three main possibilities have been considered, as follows: (1) charge transfer, i.e., the transfer of "hot" electrons, (2) energy transfer, and (3) plasmonic heating (thermal activation).

In the case of charge transfer (1), the mechanism is similar to the sensitization, and thus NMs are also named as plasmonic photosensitizers. The incident photons are absorbed by NMNPs via LSPR excitation, and then electrons might be transferred from NM to the CB of semiconductor. The electrons in CB reduce oxygen (adsorbed on the surface), as typical for semiconductor photocatalysis under aerobic conditions (same as under UV irradiation). Whereas, the electron-deficient NMNPs might oxidize some organic compounds to recover to the original zero-valent state. Many studies have proved the possibility of this mechanism in various experiments, e.g., (i) interband absorption of electrons transferred from $\mathrm{Au}$ to $\mathrm{TiO}_{2}$ by femtosecond transient absorption spectroscopy [33], (ii) the negative and positive shift of electrode potential and generation of anodic and cathodic photocurrent depending on the electrode structure, i.e., ITO/ $\mathrm{TiO}_{2} / \mathrm{Au}$ or $\mathrm{ITO} / \mathrm{Au} / \mathrm{TiO}{ }_{2}$, respectively [34,35], (iii) detection of 
different oxidation species under irradiation with UV and Vis by EPR experiments [36,37], and (iv) the conductivity under visible-light excitation only for plasmonic photocatalysts (no signal for bare titania) in the case of $\mathrm{Au} / \mathrm{TiO}_{2}$ [38] and $\mathrm{Ag} / \mathrm{TiO}_{2}$ [39] by time-resolved microwave conductivity (TRMC) study.

The energy transfer (2) between two materials might happen when their energy levels match closely, which is not expected for $\mathrm{Au} / \mathrm{TiO}_{2}$ photocatalysts as the bandgap of $\mathrm{TiO}_{2}$ (ca. 3.0-3.2 eV) is much higher than LSPR of Au NPs (ca. $2.2-2.5 \mathrm{eV}$ for spherical NPs). Accordingly, $\mathrm{TiO}_{2}$ has been first pre-modified (in order to enable visible-light absorption), e.g., PRET (plasmon resonance energy transfer) has been suggested for $\mathrm{Au}$ NPs deposited on $\mathrm{TiO}_{2}$ pre-modified with nitrogen and fluorine [40]. In the case of other Au-modified photocatalysts, e.g., pre-modified titania with nitrogen [41], narrow-bandgap semiconductors (with visible-light activity), e.g., $\mathrm{CuWO}_{4}(2.0-2.5 \mathrm{eV})$ [42], self-doped $\mathrm{TiO}_{2}$, i.e., with crystal defects [43] and amorphous $\mathrm{TiO}_{2}$ with some disorders causing the localized states inside bandgap [44], PRET has also been postulated as the main mechanism.

The plasmonic heating (3) was first suggested by Chen et al. in 2008, reporting that plasmonic heated Au NPs could induce the oxidation of organic compounds [45]. Although plasmonic heating has been proposed as the main mechanism in some research, most reports have rejected this mechanism, mainly due to usually negligible activity of unsupported Au NPs and Au-modified insulators. For example, plasmonic heating has been rejected in research on water splitting [40], photocurrent generation [46], and hydrogen dissociation [47]. The study on the activation energy has also excluded plasmonic heating for degradation of organic compounds [48] and generation of photocurrent [49].

The plasmonic photocatalysts with various morphology have been prepared that differ significantly in the composition, physicochemical properties (light absorption and reagents' adsorption), and, thus, in the overall activities. Accordingly, it is not surprising that different mechanisms have been proposed for different nanostructures. Moreover, it is also possible that complex mechanism including electron/energy transfer and even "dark" catalytic reactions [50], might be involved in the photocatalytic process.

It should be pointed out that the activity of plasmonic photocatalysts depends on the properties of both NM and semiconductor, as well as the interactions between them, e.g., uniform distribution of NM on the photocatalyst surface is usually recommended. However, in some cases, selective deposition of metals on some surfaces/facets results in improved activity [51]. For example, negligible visible-light activity has been observed for one of the most active titania photocatalysts, i.e., decahedral anatase particles (DAP), when gold has been deposited on $\{101\}$ facets, resulting probably from the fast charge carriers' recombination (electron transfer: $\mathrm{Au} \rightarrow \mathrm{TiO}_{2} \rightarrow \mathrm{Au}$ ), due to an intrinsic property of DAP, i.e., electron and hole reverse migration to $\{101\}$ and $\{001\}$ facets, respectively [52], as shown in Figure 1a,c [53]. In contrast, octahedral anatase particles (OAP) with only one type of facets $\{101\}$ exhibits the highest photocatalytic activity after modification with Au NPs, despite one of the worst photoabsorption properties (narrow LSPR), among fifteen commercial and DAP samples modified with Au NPs in the same procedure, probably due to fast migration of "hot" electrons via shallow electron traps (ETs), as shown in Figure 1b,c [54].

The photoabsorption properties of plasmonic photocatalysts depend on the kind of NM, the properties of NM deposits (size and shape), and the environment (refractive index of medium). Gold and silver have been mainly used for plasmonic photocatalysis, but also other NMs have already been applied, such as palladium [55], platinum [56], and copper [57]. For example, LSPR is observed at 520-580 nm for spherical Au NPs [58] and Cu NPs [59], and at 410-430 nm for Ag NPs [60,61]). Two absorption peaks are noticed for rod-like nanostructures with transverse and longitudinal LSPR at shorter and longer wavelengths, respectively [50]. Accordingly, it has been proposed that broader LSPR peak, e.g., due to polydispersity in NMNPs, results in the higher overall activity under visible-light irradiation due to more efficient light harvesting [32,50]. In this regard, it is expected that application of photonic crystals for plasmonic photocatalysis should result in enhanced photocatalytic performance, as discussed in the Section 4. 


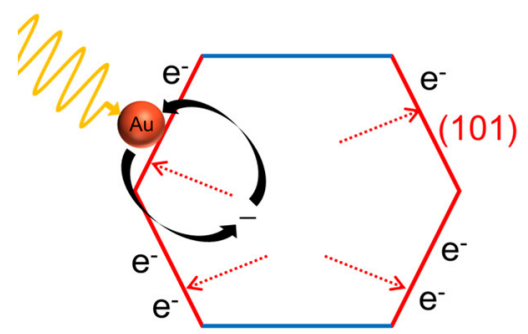

(a)

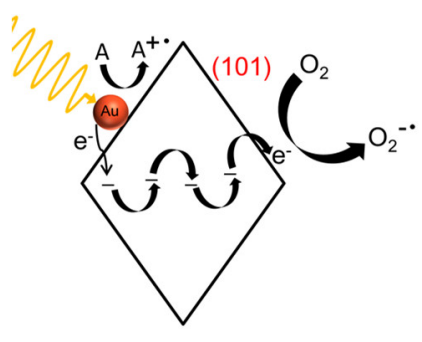

(b)

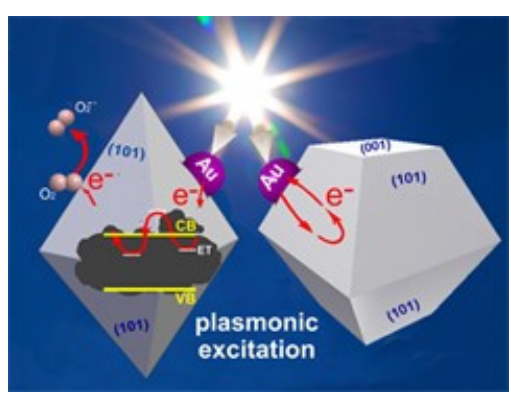

(c)

Figure 1. The mechanism of possible "hot" electron transfer on Au-modified: (a) decahedral anatase particles (DAP), (b) octahedral anatase particles (OAP), and (c) DAP vs. OAP; adapted with permission from [53]. Copyright 2018 Creative Commons Attribution.

\section{Photonic Crystals (PCs)}

Photonic crystals (PCs), periodic optical structures affecting the motion of photons, have been considered as efficient materials for light harvesting. The consistent spatial periodicity of the refractive index (n) in the well-ordered structure of PCs prevents the pathway of some wavelengths, and, thus, resulting in the formation of the stop band and the photonic bandgap (PBG) [62]. The PBG initiates the formation of "slow photons" effects at the blue and red edges of PBG. At these edges the light is scattered and reflected, resulting in the reduction of group velocity of photons [62,63]. Accordingly, it has been proposed that "slow photon" might be utilized for light harvesting of semiconductor photocatalysts.

Various nanostructures of PCs have been designed and prepared, including one-dimensional (1D), e.g., titania nanotubes-PCs (TNTs-PCs) [64,65] and three-dimensional (3D), e.g., opal PCs and inverse opal PCs (IO-PCs). In the case of 1D PCs, TNTs-PCs are prepared similarly to any other TNTs, i.e., by electrochemical methods, including one- [64] and two-step anodization [66-68]. The preparation procedure is critical for the formation and the properties of PCs [64,67]. For example, the bathochromic shift of PBG has been observed after shortening of TNTs and increasing of their diameter [65]. Moreover, the PBG position correlates directly to the distance between TNTs and their thickness.

Recently, 3D PCs of titania have been intensively examined, because of many advantages, such as large specific surface area, tunable porosity, and, thus, efficient mass transport [69-71]. IO-PCs are the exact replica structure obtained by using the opal as a template, as shown in Figure 2. The IO-PCs are usually prepared in the three-step procedure, i.e., (i) preparation of opal structure (template) by self-assembly of colloidal particles, (ii) infiltration of titania precursor (or titania) inside the pores of opal, and (iii) the removal of sacrificial template (opal). All steps are highly important for the quality (and thus optic properties) of IO-PCs to avoid the formation of any cracks and defects [72-74]. For the formation of opal structure (i), various colloidal particles have been used, such as silica $\left(\mathrm{SiO}_{2}\right)$, polystyrene (PS), and polymethyl methacrylate (PMMA). The most important for this step is the monodispersity of particles as larger variations than $5 \%$ in the size/shape inhibits the opal formation [73,75]. The self-assembly (ii) are performed by a few methods, including the vertical capillary deposition [76-78], spin coating [79], sedimentation [80], and centrifugation-assisted sedimentation [81]. Additionally, some post-thermal operations have been proposed to improve the mechanical stability and enable the good connections between the particles [82]. It has been considered that second step is the most difficult and critical, i.e., to impregnate opal with titania, obtaining the stable IO structure. Many methods have been used for this step, e.g., drop casting and capillary force [78,83], vacuum infiltration $[78,83]$, atomic layer deposition (ALD) $[84,85]$, spin-coating [86] and chemical vapor deposition (CVD) [87]. After infiltration, the crystallization of titania is usually carried out, causing ca. $15-30 \%$ shrinkage of the structure, and, thus, the pore size reduction [88-91]. The final step (iii) of the template removal might be performed by calcination (for polymers) $[77,78,83,92]$ or chemical treatment [93]. 


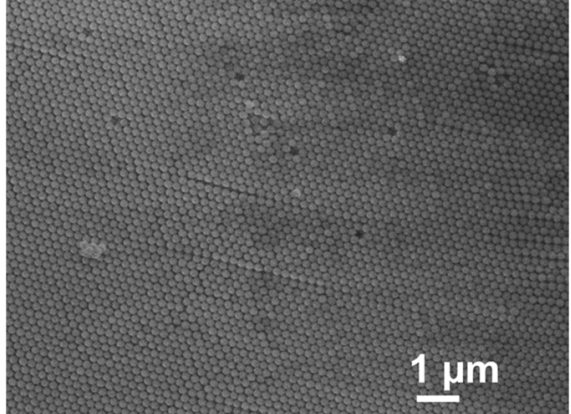

(a)

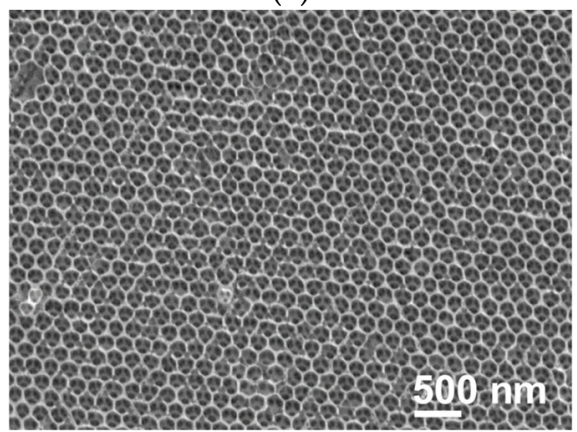

(c)

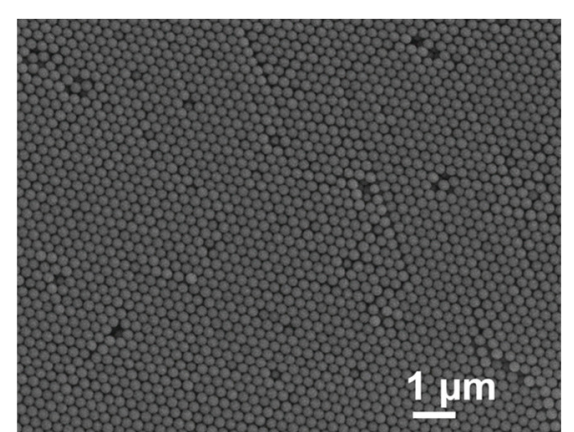

(b)

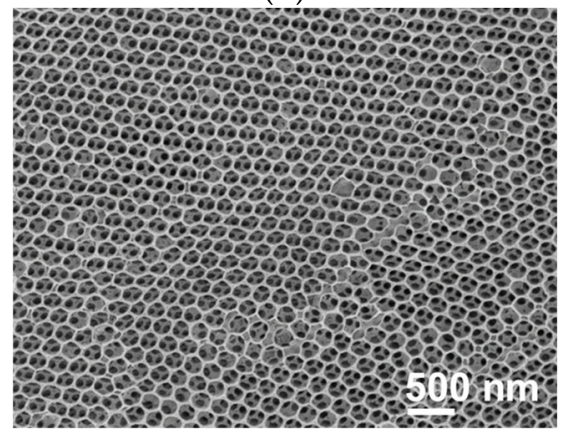

(d)

Figure 2. SEM images of opal polystyrene (PS) and inverse opal (IO) titania structures: (a,b) PS opal with: (a) 200-nm and (b) 250-nm sphere sizes, and (c,d) replicated titania IO films with: (c) 180-nm and (d) 207-nm voids; adapted with permission from [78]. Copyright 2018 Creative Commons Attribution.

The tuning of PBG might be performed by different ways, e.g., the angle of incident light and the change in the nanovoid diameter. For example, the shift of PBG towards shorter wavelengths has been observed after a decrease in nanovoid diameter caused by an increase in the calcination temperature [90]. The photocatalytic performance of titania IO-PCs have been examined under UV $[66,94]$ and Vis $[86,91,93]$ irradiation, as already summarized in review paper on titania-based photocatalysts [5]. It should be pointed out that probably the most important feature of IO is tunable nanovoid dimensions, which influences the scattering and reflection of light. Unfortunately, the contradictory results have been published. For example, it has been reported that reduced velocity of photons and inhibited charge carriers' recombination have been the most evident for structures with the largest voids of $610 \mathrm{~nm}$ [95]. In contrast, the smallest voids have been reported as the most active, giving the highest photoelectrochemical enhancements in the case of titania IO sensitized by CdS quantum dots (QDs) [84]. Therefore, the resultant photocatalytic activity might depend not only on nanovoid diameter, but also on other factors, including porosity, specific surface area and kind of co-modifications.

Besides nanovoid diameter, the slow photon effect, influenced by the angle of irradiation [83,88], impacts the photocatalytic performance. For example, hypsochromic shift of PBG has been observed after increasing the irradiation angle $[83,88,90]$, and the highest activity has been obtained under irradiation at $40^{\circ}$ than at different angles during degradation of stearic acid on IO with 247-nm voids [64]. Although, some reports have not shown the direct correlation between the voids' sizes and the photocatalytic activity [83], the slow photon effect, e.g., due to the overlapping between the red-edge of PBG and titania bandgap, results in the activity enhancement $[83,88,96]$. The comparison between the original and slightly destroyed titania IOs, e.g., by ultrasonication [94], milling [97], and grinding [89] confirms that undestroyed IO structure is necessary for high activity, e.g., 71\% decrease in activity has been observed for disordered surface by milling [97].

It should be pointed out that although titania IO might exhibit PBG in Vis range of solar spectrum (depending on the void diameter), and thus is able to absorb photons with lower energy than its 
bandgap, this absorption should not cause the photocatalytic activity as titania is not excited (transfer of electrons from VB to CB). Accordingly, even if some reports show visible-light activity of titania IOs, these reports have been mainly performed for activity testing during dyes' degradation, and thus titania sensitization by dye must be considered as the main mechanism under visible-light irradiation, but not due to PC feature. Indeed, Curti et al. have confirmed that visible-light activity of titania IO is only observed for dyes (methylene blue; MB), whereas negligible effect is obtained for non-color molecules (acetaldehyde) [88]. Tomazatou et al. have indicated that high activity of dye-sensitized titania $\mathrm{IO}\left(\mathrm{MB} / \mathrm{TiO}_{2}\right)$ under visible light (in comparison with negligible activity by commercial titania P25) is probably caused by the slow-photon effect [98]. Chen et al. have proved that overlapping of PBG with bandgap of titania $\left(\mathrm{TiO}_{2}\right.$-coated $\left.\mathrm{SnO}_{2} \mathrm{IO}\right)$ is the most recommended for activity enhancement, i.e., an increase in the activity in the following order of PBG: $2.55<2.98<3.35 \mathrm{eV}$ [99]. Moreover, it has been shown that the highest efficiency for dye decomposition has been obtained when PBG overlaps with absorption band of MB (but away from its maximum to avoid the undesired light screening), confirming both dye-sensitization mechanism and slow photon effect [100].

To further increase the photocatalytic performance by enhanced light harvesting, IO structures have been modified with various compounds, including metals, e.g., gold [79,91], silver [93], and nickel [86,101], semiconductors, e.g., cadmium selenide and cadmium sulfide QDs [84,102] and zinc oxide NPs [103], and by "self-doping" (surface-disordered-engineered $\mathrm{TiO}_{2} \mathrm{PCs}_{\text {[97]). }}$ The modifications with NM, resulting in mainly formation of plasmonic photocatalysts, are discussed in the next section.

\section{NM-Based PCs}

The heterostructural design of IOs, such as the coupling of IO-PCs with other semiconductors/materials and surface modifications with NMs, has been considered as an efficient method for enhanced performance of PCs. Although, various reasons have been proposed, including charge carriers' separation, enhanced light harvesting, synergy, higher specific surface area, it is still unclear what properties are the key-factors of high activity and which of them are the most recommended for the specific application. It is expected that for photocatalytic reactions, the most advisable modification is to use the materials with ability of photon absorption near PBG. Accordingly, the application of NM with ability of visible-light absorption seems to be highly attractive because of the possible overlapping of LSPR of NM with PBG of titania IO. Moreover, PCs-based plasmonic photocatalysts might help in the clarification on the mechanism of plasmonic photocatalysis, i.e., energy vs. electron transfer.

Recently, plasmonic PCs have been intensively investigated to combine both PBG and LSPR effects together in terms of physical appearances and electronic energies for various applications [104-109]. An interesting study has been shown for negative photoresist $\mathrm{IO}$ (prepared by $\mathrm{SiO}_{2}$ opal embedding) deposited with gold, where the dual-colored micropatterns (Figure 3) open the door for possible applications in various fields, including cosmetics, optical filters and coatings [104]. Although, there are more interesting examples of plasmonic PCs for various applications, the further discussion is limited to the photocatalytic reactions.

NM-modified PCs have already been proposed for photocatalysis, including, solar cells [40], water splitting [110] and mineralization of organic pollutants [100,111]. The extended path of light in terms of duration and length from the multi-scattering phenomenon by the PCs could be well utilized by the plasmonic NPs, resulting in efficient light harvesting, and thus enhanced quantum yield of photocatalytic reactions, as discussed in the Section 4.2. 
(a)

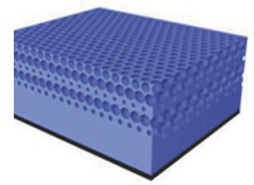

(b)

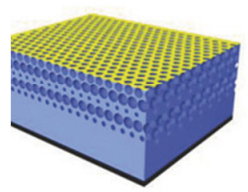

(c)

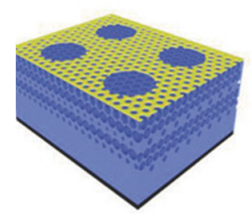

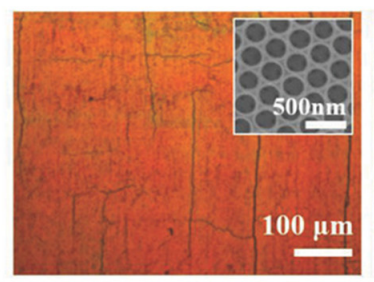
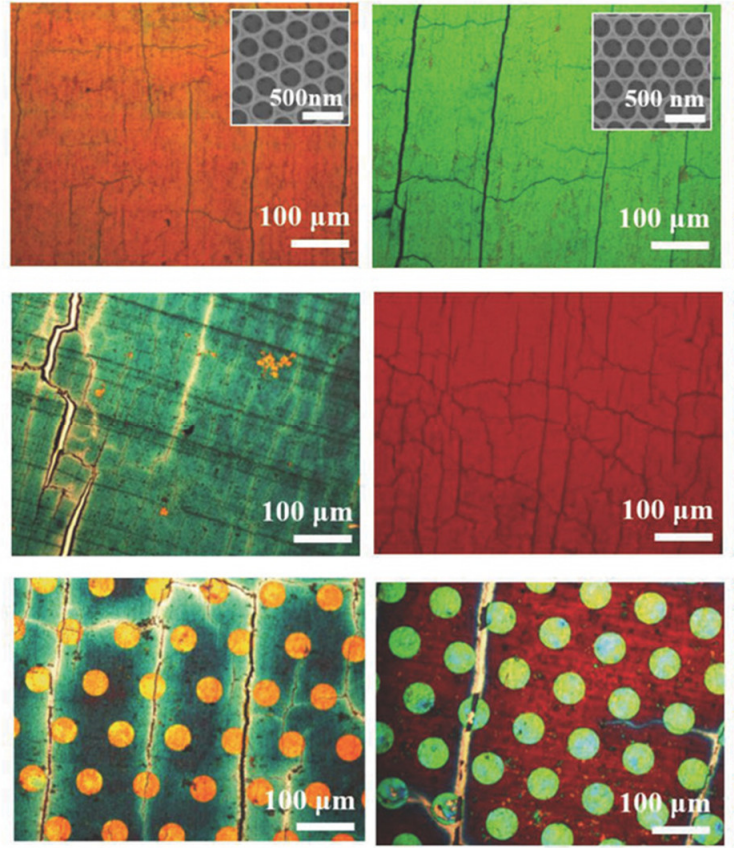
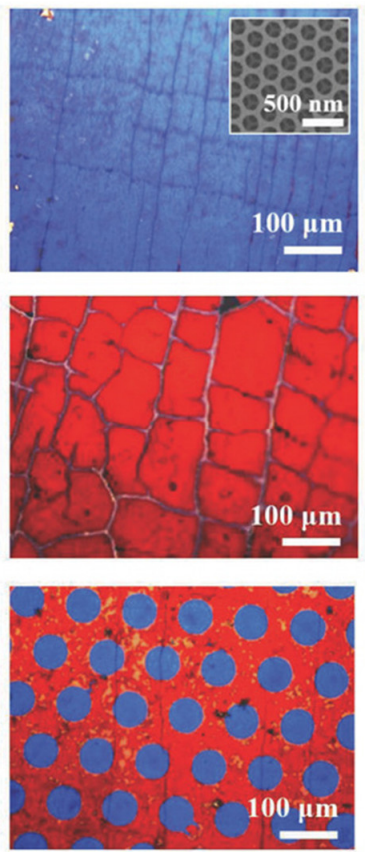

Figure 3. The models (first column) of the: (a) IO, (b) Au layer-deposited IO, and (c) micropatterned IO by local Au deposition; and respective optical microscopy images for different sizes of $\mathrm{SiO}_{2} \mathrm{NPs}_{\text {, }}$ i.e., with diameter of $315 \mathrm{~nm}$ (the second column), $290 \mathrm{~nm}$ (the third column) and $239 \mathrm{~nm}$ (the fourth column), used as a template (opal); Reprinted with permission (after formatting) from [104]. Copyright (2018) WILEY.

\subsection{Preparation of PCs-Based Plasmonic Photocatalysts}

The fabrication of PCs-based plasmonic photocatalysts is quite challenging process to load/infiltrate plasmonic NPs on/in the PCs without destroying the Bragg's diffraction property of the PCs and to retain the effective LSPR effect of NMs. The photodeposition and thermal methods have been commonly used to deposit plasmonic NPs on IO by using the adequate precursors, such as chloroplatinic acid $\left(\mathrm{H}_{2} \mathrm{PtCl}_{6}\right)$ for $\mathrm{Pt}$ [112], silver nitrate $\left(\mathrm{AgNO}_{3}\right)$ for $\mathrm{Ag}$ [113], and tetrachloroauric acid $\left(\mathrm{HAuCl}_{4}\right)$ for $\mathrm{Au}$ [106]. NMs have been deposited on $\mathrm{TiO}_{2} \mathrm{IO}$ either before [106] or after [99] its infiltration inside opal structure. Apart from that, hydrothermal method has been proposed to load Au NPs on $\mathrm{TiO}_{2}$ $\mathrm{PC}$, enhancing the stability due to the interphase sintering between $\mathrm{TiO}_{2}$ backbone and $\mathrm{Au}$ NPs [91] . Erola et al. have reported a facile method for the preparation of Ag- and Au-loaded PCs via co-assembly and infiltration methods, as shown in Figure 4 [111]. Interestingly, the co-assembly method is not suitable for Ag deposition on the $\mathrm{SiO}_{2}-\mathrm{IO}$ due to diminishing of LSPR after calcination. It has been concluded that because of less thermal stability of $\mathrm{Ag}$ than $\mathrm{Au}, \mathrm{Ag}$ is easily oxidized during calcination. Hence, the suitable method (exemplified in Table 1) must be select carefully for a good quality of PCs-based plasmonic photocatalysts.

\subsection{Photocatalytic Applications}

Although, a large number of studies on plasmonic photocatalysis has been published, only few reports might be found on PCs-based plasmonic photocatalysis. NM-modified PCs have been used in the photocatalysis field, as summarized in Table 1, due to few advantages, as follows: (i) the absorption at Vis-NIR as most of the wide-bandgap semiconductors are unable to absorb light at those regions, (ii) slow photons arising from PBG/photonic effect owning to the PCs, which might enhance and strengthen the LSPR effect, and (iii) the role of NMNPs as an electron sink, which reduces the charge carriers' recombination. Although the inhibition of recombination should not be considered as plasmonic photocatalysis, various reports point this feature, which surely might enhance the overall activity under solar radiation, i.e., at UV-Vis range. 
Table 1. Synthesis methods and activity tests for NM-modified PCs.

\begin{tabular}{|c|c|c|c|c|}
\hline Plasmonic Based PCs & Plasmonic NPs Loading/Deposition Methods & Photocatalytic Tests & Findings & References \\
\hline $\mathrm{Pt}_{\mathrm{x}} / \mathrm{PC}-\mathrm{TiO}_{2}$ & gas bubbling-assisted membrane reduction & $\begin{array}{c}\mathrm{CO}_{2} \text { reduction; } \\
\lambda=320-780 \mathrm{~nm} ; \mathrm{I} \\
\text { degradation of } 2,4-\end{array}$ & 3.2 times higher activity * & [107] \\
\hline $\mathrm{TiO}_{2} \mathrm{PC} / \mathrm{Au} \mathrm{NPs}$ & in situ hydrothermal reduction & $\begin{array}{l}\text { dichlorophenol; } \\
\lambda>420 \text { nm; II }\end{array}$ & PBG and SPR overlapping & [91] \\
\hline AgTIO & chemical route & $\begin{array}{c}\text { MB degradation; } \\
\lambda=254 \mathrm{~nm} \text { and } \\
\lambda=400-760 \mathrm{~nm} ; \mathrm{III}\end{array}$ & SPR and PBG enhancing activity & [93] \\
\hline $\mathrm{Au}-\mathrm{TiO}_{2}-\mathrm{NAA}-\mathrm{DBRs}$ & sputter coating & MB degradation; III & enhanced activity & {$[100]$} \\
\hline $\mathrm{TiO}_{2}-\mathrm{Au}-\mathrm{CdS}$ & immersion and chemical bath deposition & $\begin{array}{l}\mathrm{H}_{2} \text { production; } \\
\lambda>420 \mathrm{~nm} ; \mathrm{IV}\end{array}$ & enhanced $\mathrm{H}_{2}$ generation at blue-edge PBG & [110] \\
\hline $\mathrm{i}-\mathrm{Pt}-\mathrm{TiO}_{2}$-o film & photodeposition & $\begin{array}{l}\text { degradation of acid orange; } \\
\qquad \lambda>400 \mathrm{~nm} ; \mathrm{I}\end{array}$ & 4-fold enhancement * & [112] \\
\hline $\mathrm{Au} / \mathrm{ZnO}-\mathrm{PCs}$ & magnetron sputtering & $\begin{array}{l}\text { photodegradation of RhB; } \\
\qquad \lambda>420 \mathrm{~nm} \text {; II }\end{array}$ & 24.8-fold higher than commercial $\mathrm{ZnO}$ & [114] \\
\hline Au-PCTNTs & magnetron sputtering & $\begin{array}{c}\mathrm{CO}_{2} \text { photoreduction; } \\
\lambda>400 \mathrm{~nm} \text {; III }\end{array}$ & high selectivity of methane generation & [115] \\
\hline $\mathrm{Ag} / \mathrm{BiVO}_{4}$ & electrodeposition & $\begin{array}{l}\text { MB degradation; } \\
\lambda>420 \mathrm{~nm} ; \mathrm{III}\end{array}$ & enhanced activity & [116] \\
\hline $\mathrm{Au} / \mathrm{TNTs}$ & photodeposition & $\begin{array}{l}\text { IPCE (400-700 nm); photocurrent } \\
\quad \geq 420 \text { nm; water splitting; II }\end{array}$ & PBG matching with LSPR—enhanced activity & [117] \\
\hline $\mathrm{Au} / \mathrm{TiO}_{2}$ photoanode & $\begin{array}{l}\text { facile ionic layer adsorption and } \\
\text { thermal-reduction }\end{array}$ & $\begin{array}{c}\text { PEC water splitting; } \\
\lambda>420 \mathrm{~nm} ; \mathrm{II}\end{array}$ & $0.71 \%$ of solar energy conversion & [118] \\
\hline $\mathrm{Au} / \mathrm{TiO}_{2} \mathrm{PC}$ & chemical route & $\begin{array}{l}\text { MO degradation } \\
\lambda>420 \mathrm{~nm} \text {; III }\end{array}$ & 7-fold increase * & [119] \\
\hline $\mathrm{rGO} / \mathrm{Pt} / 3 \mathrm{DOM} \mathrm{TiO}_{2}$ & dropwise and thermal reduction & $\begin{array}{l}\text { MO degradation; } \\
\lambda>420 \mathrm{~nm} ; \mathrm{I}\end{array}$ & 4 -fold increase * & [120] \\
\hline $\mathrm{TiO}_{2}-\mathrm{IO} \mathrm{Au} / \mathrm{AgNPs}$ film & immersion & $\begin{array}{l}\text { acetylene mineralization; } \\
\qquad \lambda=365 \mathrm{~nm} ; \mathrm{I}\end{array}$ & enhanced activity * & [121] \\
\hline $\mathrm{Cu} / \mathrm{TNTs}$ & pulsed electrochemical deposition & $\begin{array}{l}\mathrm{H}_{2} \text { production } \\
\lambda>400 \mathrm{~nm} ; \mathrm{II}\end{array}$ & enhanced activity & [122] \\
\hline
\end{tabular}

AgTIO- $\mathrm{TiO}_{2}$ IO films loaded with Ag NPs; i-Pt-TiO ${ }_{2}$-o film—- $\mathrm{TiO}_{2}$ IO loaded with Pt nanoclusters; $\mathrm{MB}$-methylene blue; $\mathrm{MO}$-methyl orange; NAA-DBRs—-functionalized nanoporous anodic alumina distributed Bragg reflectors; $\mathrm{PEC}$ - photoelectrochemical; $\mathrm{PCTNTs}-\mathrm{PCs}$ consisting of $\mathrm{TiO}_{2}$ nanotube arrays; $\mathrm{rGO} / \mathrm{Pt} / 3 \mathrm{DOM}$ TiO $2-3 \mathrm{D}$-ordered macroporous TiO 2 with $\mathrm{Pt}$ and reduced graphene oxide; RhB —rhodamine B; * activity in the comparison with the reference sample; excitation of: I—semiconductor, II—NM, III—both (semiconductor and NM), IV—co-modifier (CdS). 


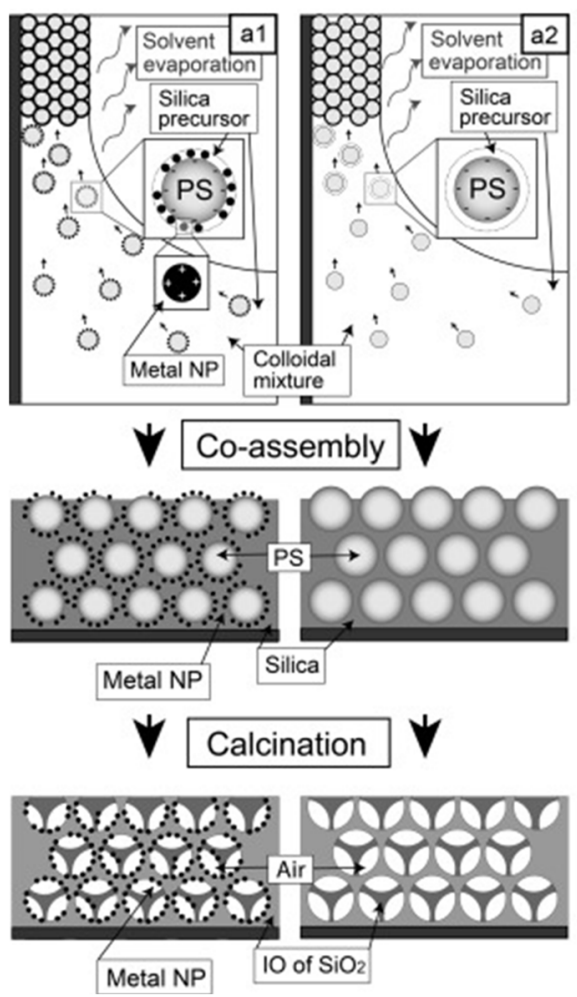

(a)

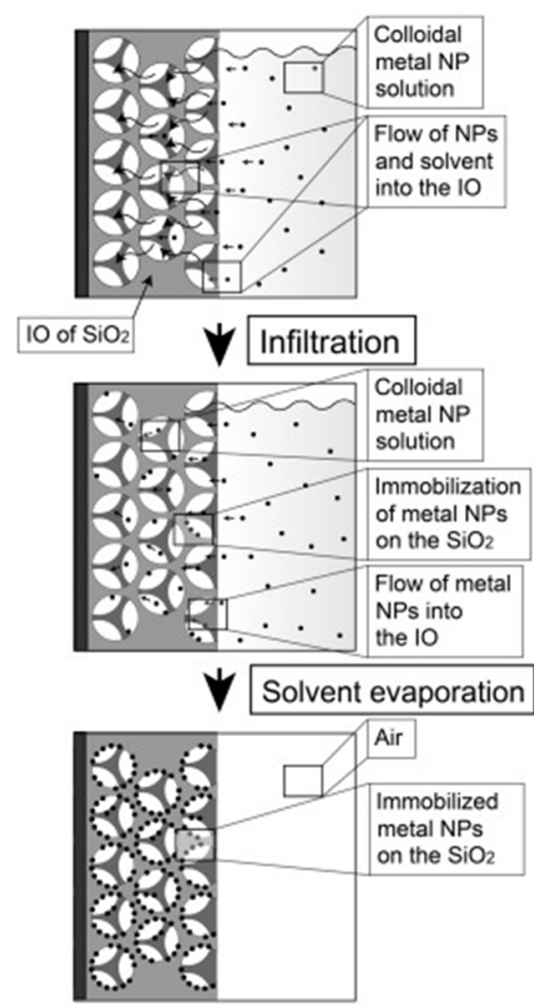

(b)

Figure 4. Fabrication of $\mathrm{SiO}_{2}$ photonic crystal (PC) films using: (a) co-assembly method in which PCs were prepared with (a1) and without (a2) positively charged metal NPs and (b) infiltration method; Reprinted with permission (after formatting) from [111]. Copyright (2015) Elsevier.

However, the aspect mentioned at (ii) should be only expected if LSPR matches with the slow photons effect, which could be realized by the perfect tuning in the fabrication process. Indeed, even a decrease in the photocatalytic activity of $\mathrm{TiO}_{2}$-coated nanoporous alumina $\mathrm{IO}$ has been observed after deposition of Au NPs or Ag NPs on its surface, where both effects do not match, i.e., LSPR at ca. 400-550 nm and PBG at ca. $800 \mathrm{~nm}$ [100]. In contrast, Lu et al. have succeeded the precise tuning in fabrication of $\mathrm{Au}-\mathrm{NP} / \mathrm{TiO}_{2} \mathrm{PC}$ with LSPR overlapping with the blue edge of PBG, resulting in 2.3-fold higher photocatalytic efficiency for photodegradation of 2,4-dichlorophenol in comparison to the reference Au-NP/nanocrystalline $\mathrm{TiO}_{2}$ under visible-light irradiation [91]. Similarly, Zhang et al. [118] have shown the enhanced photoelectrochemical (PEC) water splitting by using the Au-NP-modified $\mathrm{TiO}_{2}$ nanorod array structure ( $\mathrm{Au} / \mathrm{TiO}_{2}$ NRPCs) by overlapping of LSPR with red edge of PBG effect (Figure 5), utilizing the slow photons (max at ca. $518 \mathrm{~nm}$ ). Additionally, both studies $[91,118]$ have indicated that red-edge PBG is more effective than blue-edge one. At the red-edge PBG, the light propagate with decrease group velocity, being described as a sinusoidal standing wave that has its highest amplitude in the high refractive index part of the PCs, whereas the standing wave at blue edge is localized in the low-refractive index part. Accordingly, an absorber at high dielectric part has stronger interactions with light at red-edge regions of PBG. Similarly, IO-molybdenum: bismuth vanadium $(\mathrm{Mo:BiVO} 4)$ photoelectrode with infiltrated $\mathrm{Au}$ NPs has shown an increase in PEC water splitting, and the enhancement has been attributed to the amplified LSPR effect when the polystyrene (PS) template of 260-nm particles results in PBG at $513 \mathrm{~nm}$, synergistically matching with the LSPR of $\mathrm{Au}$ [123].

An important aspect that should be considered for 3D powdered PC-based plasmonic photocatalysts is the periodical/structural integrity as disordered structure could affect the enhancement of the visible-light harvesting, thus reducing the photocatalytic performance. Indeed, the crushed $\mathrm{Au} / \mathrm{TiO}_{2}$ biomorphic (BM)PCs have exhibited lower photodegradation efficiency (Figure 6) as compared 
with uncrushed ones [120]. Similarly, C. Dinh et al. have shown that the crushed $\mathrm{Au} / \mathrm{TiO}_{2}-3 \mathrm{D}$ hollow nanospheres (HNSs) show about 4.3-fold lower efficiency of $\mathrm{CO}_{2}$ generation from photodecomposition of isopropanol as compared with an original $\mathrm{Au} / \mathrm{TiO}_{2}-3 \mathrm{DHNS}$, indicating the probability of a decrease in photoabsorption ability by $\mathrm{Au}$, due to the structure disruption [124]. It should be pointed out that although the partial crushing of IO structure results in a decrease in the activity in both studies, those activities have been much higher than that by a reference sample of commercial titania modified with $\mathrm{Au} \mathrm{NPs}\left(\mathrm{Au} / \mathrm{TiO}_{2}-\mathrm{P} 25\right)$, highlighting the synergism between the periodic porous structure (although slightly destroyed) and plasmonic effect.

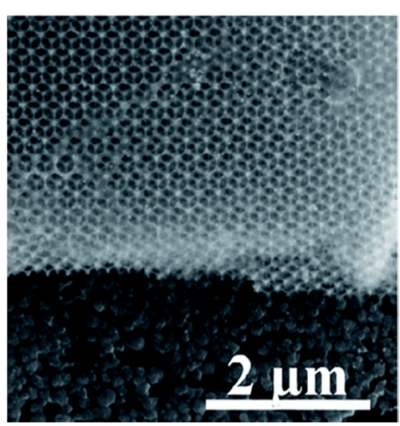

(a)

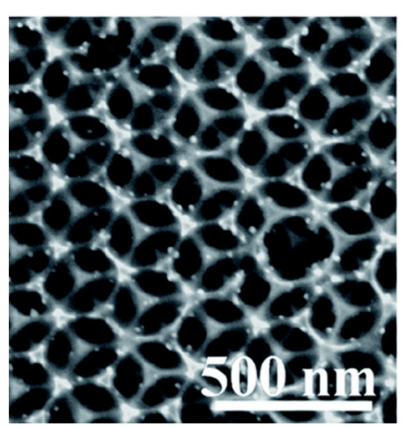

(b)

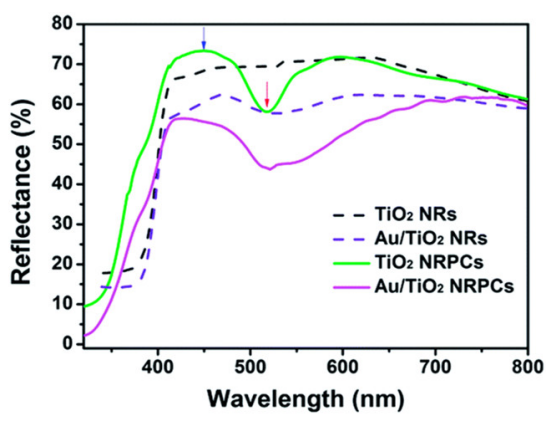

(c)

Figure 5. (a) Low-magnification and (b) high-resolution scanning electron microscopy images of $\mathrm{Au} / \mathrm{TiO}_{2}$ PCs on the fluorine-doped tin oxide (FTO) substrate, (c) Diffused reflectance spectra of $\mathrm{TiO}_{2}$ nanorods (NRs), $\mathrm{Au} / \mathrm{TiO}_{2} \mathrm{NRs}, \mathrm{TiO}_{2} \mathrm{NRPCs}, \mathrm{Au} / \mathrm{TiO}_{2}$ NRPCs (PBG marked with dark arrow and slow-photon region marked with red arrow); Reprinted with permission (after formatting) from [118]. Copyright (2014) RSC.

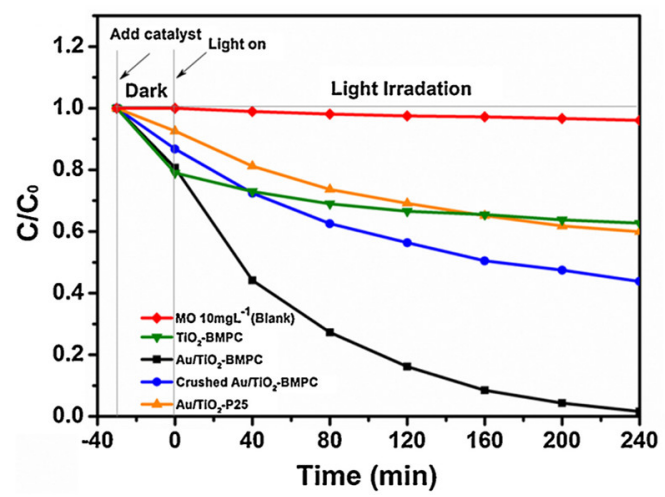

(a)

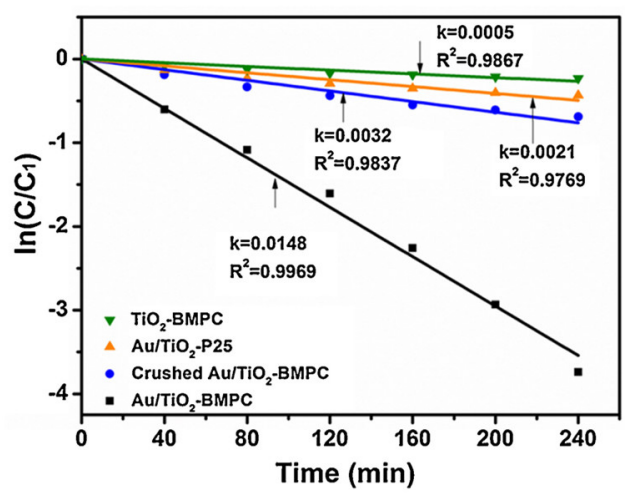

(b)

Figure 6. The time course of the photocatalytic degradation of $\mathrm{MO}$ under visible-light irradiation $(\lambda>420 \mathrm{~nm})$ using bare PCs $\left(\mathrm{TiO}_{2}-\mathrm{BMPC}\right)$, Au-modified PCs $\left(\mathrm{Au} / \mathrm{TiO}_{2}-\mathrm{BMPC}\right)$, crushed Au-modified PCs $\left(\mathrm{Au} / \mathrm{TiO}_{2}-\mathrm{BMPC}\right)$ and commercial titania modified with $\mathrm{Au} \mathrm{NPs}\left(\mathrm{Au} / \mathrm{TiO}_{2}-\mathrm{P} 25\right)$ : (a) a decrease in the concentration of dye during degradation $\left(C / C_{0}\right)$, and $(\mathbf{b})$ the respective logarithm plots; Reprinted with permission (after formatting) from [120]. Copyright (2016) Elsevier.

NMNPs are known for their ability to inhibit the recombination of charge carriers, by trapping electrons (as already discussed in Introduction). It should be underlined that this effect could not be described as plasmonic photocatalysis since the semiconductor is excited, but not NM. Accordingly, NMNPs, such as Pt, Au, and Ag have been infiltrated/incorporated on PCs to enhance the photocatalytic activity $[93,125]$. For example, Huo et al. have shown a facile preparation method of NM-modified $\mathrm{PC}$ s by incorporation of $\mathrm{Pt} \mathrm{NPs}$ and reduced graphene oxide (r-GO) on $\mathrm{TiO}_{2} \mathrm{IO}$ macroporous structure (Figure 7a), highlighting the enhanced photodegradation of methyl orange [123]. However, it should be pointed out that this study could not be considered as plasmonic photocatalysis as $\mathrm{TiO}_{2}$ instead of NM is excited, as shown in Figure $7 \mathrm{~b}$. In contrast, Temerov et al. have discussed the enhanced 
mineralization of acetylene to $\mathrm{CO}_{2}$ on $\mathrm{TiO}_{2}-\mathrm{IO}$ modified with Au NPs and $\mathrm{Ag}$ NPs (by $53 \%$ and $39 \%$, respectively), owning to the LSPR activation (plasmonic photocatalysis), i.e., electron transfer from $\mathrm{NM}$ to $\mathrm{TiO}_{2}$ with simultaneous oxidation of acetylene on the NM surface, but irradiation has been performed with UVA, and thus $\mathrm{TiO}_{2}$ excitation must also be considered [124].

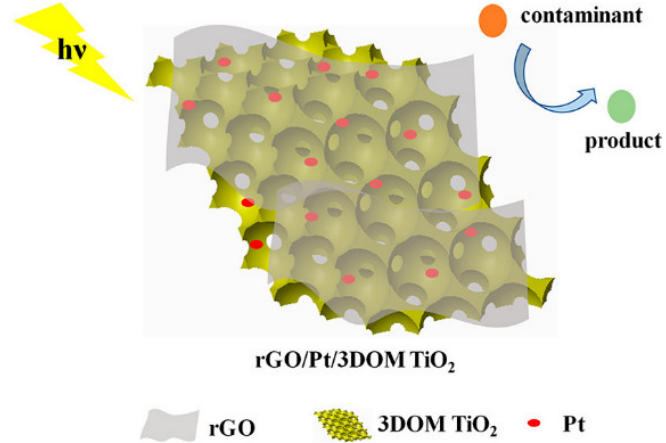

(a)

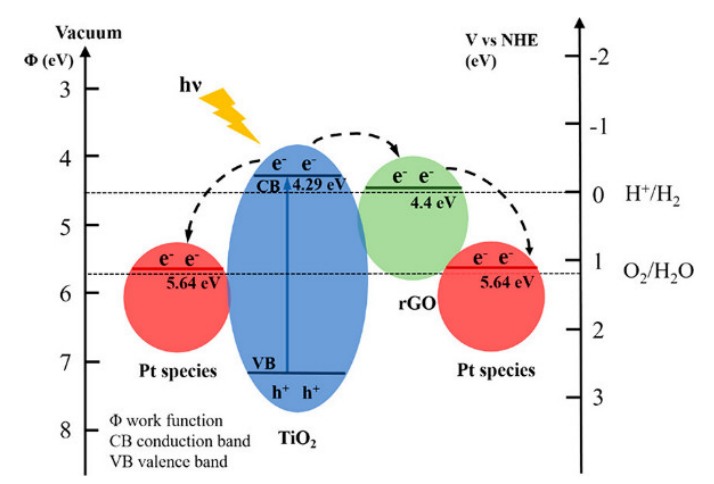

(b)

Figure 7. Schematic illustrations of: (a) the morphology of $\mathrm{TiO}_{2} \mathrm{IO}$ co-modified with Pt NPs and reduced graphene oxide (r-GO), and (b) the proposed charge carriers' separation and migration in $\mathrm{rGO} / \mathrm{Pt} / \mathrm{TiO}_{2}$ (not plasmonic activation); Reprinted with permission from [123]. Copyright (2019) ACS.

Interestingly, plasmonic photocatalysis using both functions of NMs, i.e., plasmonic excitation and inhibition of charge carriers' recombination, has been proposed by Rahul et al. for bi-metal-modified $\mathrm{TiO}_{2}-\mathrm{IO}$ co-doped with N/F [106]. The LSPR excitation of Au results in an electron transfer from Au to $\mathrm{CB}$ of $\mathrm{TiO}_{2}$, and then to co-deposited Pt NPs, on which $\mathrm{H}_{2}$ evolution takes place, as shown in Figure 8 . It should be pointed out that co-catalyst is necessary for efficient $\mathrm{H}_{2}$ evolution on titania, and $\mathrm{Pt}$ is probably the most active co-catalyst for this reaction [5,126].

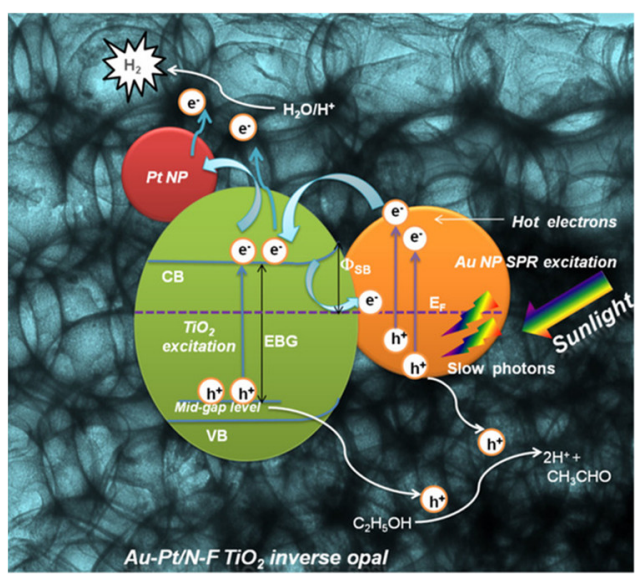

(a)

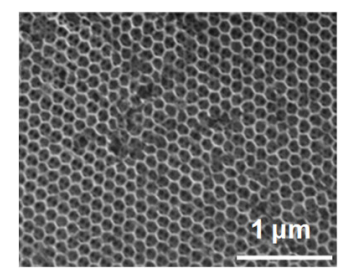

(b)

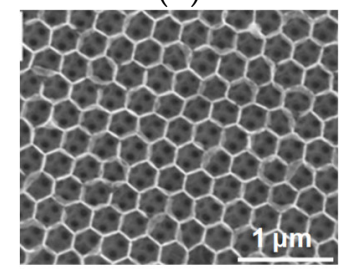

(d)

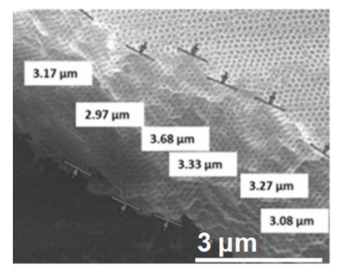

(c)

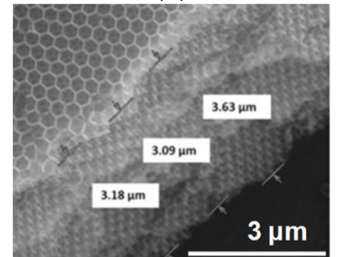

(e)

Figure 8. (a) Schematic illustration of the proposed mechanism of $\mathrm{H}_{2}$ generation over $\mathrm{Au}-\mathrm{Pt} / \mathrm{N}-\mathrm{F} \mathrm{TiO} 2$ IO-460 under solar light irradiation; SEM images of: (b,c) Au-Pt/ N-F TiO 2 IO-215: (b) top view and (c) cross section view, and (d,e) $\mathrm{Au}-\mathrm{Pt} / \mathrm{N}-\mathrm{F} \mathrm{TiO} 2 \mathrm{IO}-460$ : (d) top view and (e) cross section view; Reprinted with permission (after formatting) from [106]. Copyright (2018) WILEY.

In the case of NM deposition on the PCs, the amount of NM is critical for the enhancement of the photocatalytic activity. For example, $2 \mathrm{wt}$. $\%$ of $\mathrm{Pt}$ loading on $\mathrm{TiO}_{2}-\mathrm{IO} \mathrm{PC}$ has been shown as the best, whereas $1.3 \mathrm{wt} . \%$ is not able to exhibit any amplification in the dye photodegradation [112]. Similarly, it has been shown that the lowest $(2 \mathrm{mM})$ and the highest $(20 \mathrm{mM})$ amount of deposited $\mathrm{Ag}$ (in terms of precursor concentration) on $\mathrm{TiO}_{2} \mathrm{PC}$ is not able to amplify the light absorption as 
the former is inadequate to exhibit LSPR and the latter results in Ag NPs' aggregation, diminishing the activity [93]. An interesting study has been shown for the correlation between Ag-NP deposition duration $(15,30,45$, and $60 \mathrm{~s})$ by pulse current deposition on $\mathrm{TiO}_{2}-\mathrm{IO}$ and the photocatalytic activity, as shown in Figure 9 [99]. Longer deposition duration has resulted in the formation of Ag aggregates (Figure 9c), which directly affects the MB photodegradation efficiency, due to the loss of LSPR effect (the aggregation) and blockage of the charge carriers' migration. Similarly, S. Zhang et al. have shown that the number of deposition cycles of $\mathrm{Cu}$ NPs on $\mathrm{TiO}_{2}$ nanotube arrays (TNTs) affects the efficiency of photocatalytic water splitting, and 20 cycles results in 10.7-fold higher evolution of $\mathrm{H}_{2}$ as compared to the reference sample (without $\mathrm{Cu}$ ), due to the amplified plasmonic excitation [126]. Although further increase in deposition cycles $(>20)$ has reduced the photocatalytic activity (non-clarified reason), the efficiency has been much higher than that by non-modified TNTs.

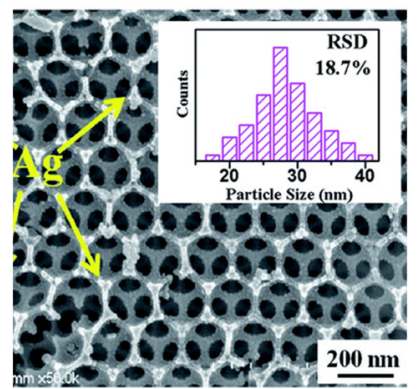

(a)

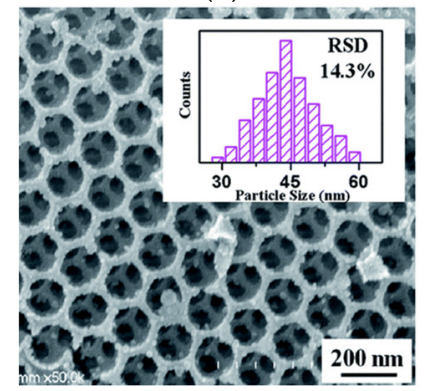

(c)

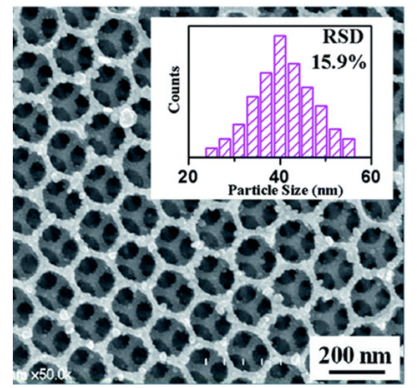

(b)

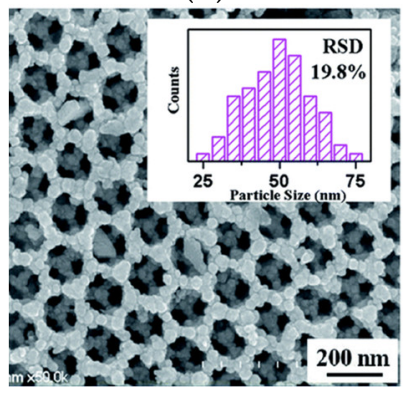

(d)

Figure 9. SEM images of PCs modified with Ag by the pulsed current deposition method during: (a) $15 \mathrm{~s}-\mathrm{Ag} / \mathrm{TiO}_{2}$, (b) $30 \mathrm{~s}-\mathrm{Ag} / \mathrm{TiO}_{2}$, (c) $45 \mathrm{~s}-\mathrm{Ag} / \mathrm{TiO}_{2}$, and (d) $60 \mathrm{~s}-\mathrm{Ag} / \mathrm{TiO}_{2}$; Reprinted with permission (after formatting) from [99]. Copyright (2014) RSC.

Moreover, it has also been postulated that the localization of NM in/on PCs might be crucial for the overall activity. For example, Lim et al. have proposed that deposition of NM layer on PCs is not recommended, as the majority of light is absorbed in the metallic coating before it reaches the bulk PCs structure, resulting in a decrease in the overall photocatalytic activity, similar to well-known "screen-effect" in other $\mathrm{NM}-\mathrm{TiO}_{2}$ structures [5,12]. Accordingly, it has been proposed that the preparation of titania IO structures with NMNPs inside each void would be the most profitable. In this regard, the size of NMNPs as well as void diameter should be tuned well to allow the matching between LSPR of NM and PBG of $\mathrm{TiO}_{2}$. Our recent study on Au NPs deposited in voids of $\mathrm{TiO}_{2} \mathrm{IOs}$ has confirmed the high enhancement of activity under irradiation with wavelengths correlating with LSPR of Au NPs and PBG of $\mathrm{TiO}_{2} \mathrm{IO}$ (unpublished data [127]).

\section{Conclusions}

Plasmonic photocatalysis is probably one of the hottest topics in heterogeneous photocatalysis research because of possible applications under broad wavelength ranges (UV/Vis/NIR). Although, the research is quite new, there are many reports on preparation, characterization, activity and stability enhancement, mechanism clarifications, including various applications, e.g., solar energy conversion, 
degradation of chemical and microbiological pollutants and $\mathrm{CO}_{2}$ conversion. However, the low quantum yields of photocatalytic reactions under visible-light irradiation are critical for the overall activity and possible applications. Accordingly, enhanced light harvesting is highly important for the activity enhancement. PCs seem to be the best materials for efficient light utilization. However, it should be pointed out that PBG and slow photon effects at Vis/NIR range of solar radiation should not be able to excite wide-bandgap semiconductors, due to insufficient energy. Although, some reports show photocatalytic activity of bare $\mathrm{TiO}_{2} \mathrm{IO}$ structures, those studies have been mainly performed for dyes, resulting in titania sensitization by dyes. However, PCs-based plasmonic photocatalysts due to LSPR absorption have been promising candidates for high photocatalytic performance. Accordingly, such photocatalysts have been synthesized, characterized and tested. However, the preparation of both PCs and PCs-based plasmonic photocatalysts is quite challenging, involving multi-step procedures.

It has been proposed that precise and fine tuning of photoabsorption properties, i.e., PBG matching with LSPR by nanoarchitecture of PCs void diameter and NMNPs size, respectively, is the most important aspect for the PCs-based plasmonic photocatalysts. It should be pointed out that the content of NM and structure configuration might be also a key-factor for photocatalytic activity. For example, too low content of NMs result in low LSPR, whereas too large content might cause NPs aggregation. The deposition of NMs on the surface of IO might also block the light (screening effect). Accordingly, it is proposed that the preparation of PCs with NM deposited in voids would be the most recommended for efficient light harvesting, and, thus, the overall photocatalytic effect.

Author Contributions: Conceptualization, E.K.; writing-original draft preparation, T.R.-M. and E.K.; writing-review and editing, B.O. and E.K. All authors have read and agreed to the published version of the manuscript.

Funding: This research was funded by Japanese Government (Monbukagakusho: MEXT) Scholarship. The APC was funded by E.K.

Conflicts of Interest: The authors declare no conflict of interest.

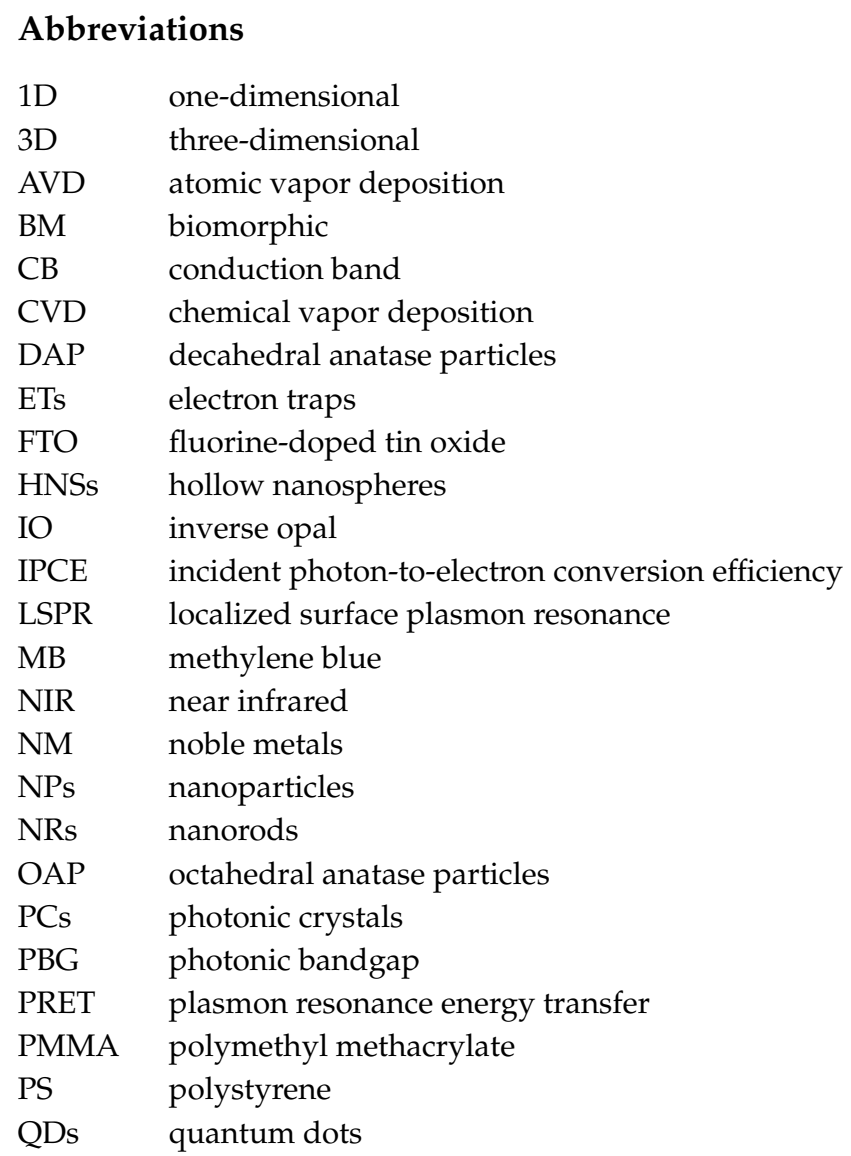




$\begin{array}{ll}\text { r-GO } & \text { reduced graphene oxide } \\ \text { TNTs } & \text { titania nanotubes } \\ \text { UV } & \text { ultraviolet } \\ \text { VB } & \text { valence band } \\ \text { Vis } & \text { visible light }\end{array}$

\section{References}

1. Hoffmann, M.R.; Martin, S.T.; Choi, W.Y.; Bahnemann, D.W. Environmental applications of semiconductor photocatalysis. Chem. Rev. 1995, 95, 69-96. [CrossRef]

2. Nakata, K.; Fujishima, A. $\mathrm{TiO}_{2}$ photocatalysis: Design and applications. J. Photochem. Photobiol. 2012, 13, 169-189. [CrossRef]

3. Ohtani, B. Photocatalysis A to Z-What we know and what we do not know in a scientific sense. J. Photochem. Photobiol. 2010, 11, 157-178. [CrossRef]

4. Abe, R. Recent progress on photocatalytic and photoelectrochemical water splitting under visible light irradiation. J. Photochem. Photobiol. 2010, 11, 179-209. [CrossRef]

5. Wang, K.L.; Janczarek, M.; Wei, Z.S.; Raja-Mogan, T.; Endo-Kimura, M.; Khedr, T.M.; Ohtani, B.; Kowalska, E. Morphology- and crystalline composition-governed activity of titania-based photocatalysts: Overview and perspective. Catalysts 2019, 9, 1054. [CrossRef]

6. Herrmann, J.M. Heterogeneous photocatalysis: Fundamentals and applications to the removal of various types of aqueous pollutants. Catal. Today 1999, 53, 115-129. [CrossRef]

7. Zaleska, A. Doped-TiO 2 : A review. Rec. Patent. Eng. 2008, 2, 157-164. [CrossRef]

8. Kraeutler, B.; Bard, A.J. Heterogeneous photocatalytic preparation of supported catalysts. Photodeposition of platinum on $\mathrm{TiO}_{2}$ powder and other substrates. J. Am. Chem. Soc. 1978, 100, 4317-4318. [CrossRef]

9. Nishimoto, S.I.; Ohtani, B.; Kagiya, T. Photocatalytic dehydrogenation of aliphatic-alcohols by aqueous suspensions of platinized titanium-dioxide. J. Chem. Soc. Farad. Trans. 1985, 81, 2467-2474. [CrossRef]

10. Pichat, P.; Herrmann, J.M.; Disdier, J.; Courbon, H.; Mozzanega, M.N. Photocatalytic hydrogen production from aliphatic alcohols over a bifunctional platinum on titanium dioxide catalyst. Nouv. J. Chim. 1981, 5, 627-636.

11. Bahnemann, D.W.; Mönig, J.; Chapman, R. Efficient photocatalysis of the irreversible one-electron and two-electron reduction of halothane on platinized colloidal titanium dioxide in aqueous suspension. J. Phys. Chem. 1987, 91, 3782-3788. [CrossRef]

12. Wang, K.L.; Wei, Z.S.; Ohtani, B.; Kowalska, E. Interparticle electron transfer in methanol dehydrogenation on platinum-loaded titania particles prepared from P25. Catal. Today 2018, 303, 327-333. [CrossRef]

13. Macyk, W.; Burgeth, G.; Kisch, H. Photoelectrochemical properties of platinum (IV) chloride surface modified $\mathrm{TiO}_{2}$. Photochem. Photobiol. Sci. 2003, 2, 322-328. [CrossRef]

14. Kowalska, E.; Remita, H.; Colbeau-Justin, C.; Hupka, J.; Belloni, J. Modification of titanium dioxide with platinum ions and clusters: Application in photocatalysis. J. Phys. Chem. 2008, 112, 1124-1131. [CrossRef]

15. Tian, Y.; Tatsuma, T. Mechanisms and applications of plasmon-induced charge separation at $\mathrm{TiO}_{2}$ films loaded with gold nanoparticles. J. Am. Chem. Soc. 2005, 127, 7632-7637. [CrossRef] [PubMed]

16. Verbruggen, $\mathrm{S} . \mathrm{W}$. $\mathrm{TiO}_{2}$ photocatalysis for the degradation of pollutants in gas phase: From morphological design to plasmonic enhancement. J. Photochem. Photobiol. 2015, 24, 64-82. [CrossRef]

17. Kowalska, E. Plasmonic photocatalysis. In Gold Nanoparticles for Physics, Chemistry and Biology, 2nd ed.; Louis, C., Pluchery, O., Eds.; World Scientific: Singapore, 2017; pp. 319-364.

18. Ueno, K.; Misawa, H. Surface plasmon-enhanced photochemical reactions. J. Photochem. Photobiol. 2013, 15, 31-52. [CrossRef]

19. Sarina, S.; Waclawik, E.R.; Zhu, H.Y. Photocatalysis on supported gold and silver nanoparticles under ultraviolet and visible light irradiation. Green Chem. 2013, 15, 1814-1833. [CrossRef]

20. Kowalska, E. Plasmonic Photocatalysts. Available online: https://www.mdpi.com/journal/catalysts/special_ issues/plasmonic_photocatal (accessed on 2 July 2020).

21. Verbruggen, S.W. Functional Plasmonic Nanostructures. Available online: https://www.mdpi.com/journal/ nanomaterials/special_issues/functional_plasmonic (accessed on 2 July 2020). 
22. Kominami, H.; Tanaka, A.; Hashimoto, K. Mineralization of organic acids in aqueous suspension of gold nanoparticles supported on cerium (IV) oxide powder under visible light irradiation. Chem. Commun. 2010, 46, 1287-1289. [CrossRef]

23. Thimsen, E.; Le Formal, F.; Gratzel, M.; Warren, S.C. Influence of plasmonic Au nanoparticles on the photoactivity of $\mathrm{Fe}_{2} \mathrm{O}_{3}$ electrodes for water splitting. Nano Lett. 2011, 11, 35-43. [CrossRef]

24. Yu, H.; Ming, H.; Zhang, H.; Li, H.; Pan, K.; Liu, Y.; Wang, F.; Gong, J.; Kang, Z. Au/ZnO nanocomposite: Facile fabrication and enhanced photocatalytic activity for degradation of benzene. Mater. Chem. Phys. 2012, 137, 113-117. [CrossRef]

25. Lan, J.Y.; Zhou, X.M.; Liu, G.; Yu, J.G.; Zhang, J.C.; Zhi, L.J.; Nie, G.J. Enhancing photocatalytic activity of one-dimensional $\mathrm{KNbO}_{3}$ nanowires by Au nanoparticles under ultraviolet and visible-light. Nanoscale 2011, 3, 5161-5167. [CrossRef]

26. Kashyap, T.; Biswasi, S.; Pal, A.R.; Choudhury, B. Unraveling the catalytic and plasmonic roles of g- $\mathrm{C}_{3} \mathrm{~N}_{4}$ supported Ag and Au nanoparticles under selective photoexcitation. ACS Sustain. Chem. Eng. 2019, 7, 19295-19302. [CrossRef]

27. Xu, H.; Li, H.M.; Xia, J.X.; Yin, S.; Luo, Z.J.; Liu, L.; Xu, L. One-pot synthesis of visible-light-driven plasmonic photocatalyst Ag/AgCl in ionic liquid. ACS Appl. Mater. Interfaces 2011, 3, 22-29. [CrossRef] [PubMed]

28. Wang, Z.L.; Zhang, J.F.; Lv, J.L.; Dai, K.; Liang, C.H. Plasmonic $\mathrm{Ag}_{2} \mathrm{MoO}_{4} / \mathrm{AgBr} / \mathrm{Ag}$ composite: Excellent photocatalytic performance and possible photocatalytic mechanism. Appl. Surf. Sci. 2017, 396, 791-798. [CrossRef]

29. Del Tedesco, A.; Piotto, V.; Sponchia, G.; Hossain, K.; Litti, L.; Peddis, D.; Scarso, A.; Meneghetti, M.; Benedetti, A.; Riello, P. Zirconia-based magnetoplasmonic nanocomposites: A new nanotool for magnetic-guided separations with SERS identification. ACS Appl. Nano Mater. 2020, 3, 1232-1241. [CrossRef]

30. Subramanian, V.; Wolf, E.; Kamat, P.V. Semiconductor-metal composite nanostructures. To what extent do metal nanoparticles improve the photocatalytic activity of $\mathrm{TiO}_{2}$ films? J. Phys. Chem. 2001, 105, 11439-11446. [CrossRef]

31. Rodriguez-Gonzalez, V.; Zanella, R.; del Angel, G.; Gomez, R. MTBE visible-light photocatalytci decomposition over $\mathrm{Au} / \mathrm{TiO}_{2}$ and $\mathrm{Au} / \mathrm{TiO}_{2}-\mathrm{Al}_{2} \mathrm{O}_{3}$ sol-gel prepared catalysts. J. Mol. Catal. Chem. 2008, 281, 93-98. [CrossRef]

32. Kowalska, E.; Abe, R.; Ohtani, B. Visible light-induced photocatalytic reaction of gold-modified titanium(IV) oxide particles: Action spectrum analysis. Chem. Commun. 2009, 2, 241-243. [CrossRef]

33. Furube, A.; Du, L.; Hara, K.; Katoh, R.; Tachiya, M. Ulltrafast plasmon-induced electron transfer from gold nanodots into $\mathrm{TiO}_{2}$ nanoparticles. J. Am. Chem. Soc. 2007, 129, 14852-14853. [CrossRef] [PubMed]

34. Sakai, N.; Fujiwara, Y.; Arai, M.; Yu, K.; Tatsuma, T. Electrodeposition of gold nanoparticles on ITO: Control of morphology and plasmon resonance-based absorption and scattering. J. Electroanal. Chem. 2009, 628, 7-15. [CrossRef]

35. Sakai, N.; Fujiwara, Y.; Takahashi, Y.; Tatsuma, T. Plasmon-resonance-based generation of cathodic photocurrent at electrodeposited gold nanoparticles coated with $\mathrm{TiO}_{2}$ films. Chem. Phys. Chem. 2009, 10, 766-769. [CrossRef] [PubMed]

36. Caretti, I.; Keulemans, M.; Verbruggen, S.W.; Lenaerts, S.; Van Doorslaer, S. Light-induced processes in plasmonic gold/ $\mathrm{TiO}_{2}$ photocatalysts studied by electron paramagnetic resonance. Top. Catal. 2015, 58, 776-782. [CrossRef]

37. Priebe, J.B.; Radnik, J.; Lennox, A.J.J.; Pohl, M.M.; Karnahl, M.; Hollmann, D.; Grabow, K.; Bentrup, U.; Junge, H.; Beller, M.; et al. Solar hydrogen production by plasmonic $\mathrm{Au}-\mathrm{TiO}_{2}$ catalysts: Impact of synthesis protocol and $\mathrm{TiO}_{2}$ phase on charge transfer efficiency and $\mathrm{H}_{2}$ evolution rates. ACS Catal. 2015, 5, 2137-2148. [CrossRef]

38. Mendez-Medrano, M.G.; Kowalska, E.; Lehoux, A.; Herissan, A.; Ohtani, B.; Rau, S.; Colbeau-Justin, C.; Rodriguez-Lopez, J.L.; Remita, H. Surface modification of $\mathrm{TiO}_{2}$ with $\mathrm{Au}$ nanoclusters for efficient water treatment and hydrogen generation under visible light. J. Phys. Chem. 2016, 120, 25010-25022. [CrossRef]

39. Wei, Z.; Janczarek, M.; Endo, M.; Colbeau-Justin, C.; Ohtani, B.; Kowalska, E. Silver-modified octahedral anatase particles as plasmonic photocatalyst. Catal. Today 2018, 310, 19-25. [CrossRef]

40. Liu, Z.; Hou, W.; Pavaskar, P.; Aykol, M.; Cronin, S.B. Plasmon resonance enhancement of photocatalytic water splitting under visible illumination. Nano Lett. 2011, 11, 1111-1116. [CrossRef] 
41. Bouhadoun, S.; Guillard, C.; Dapozze, F.; Singh, S.; Amans, D.; Boucle, J.; Herlin-Boime, N. One step synthesis of $\mathrm{N}$-doped and $\mathrm{Au}$-loaded $\mathrm{TiO}_{2}$ nanoparticles by laser pyrolysis: Application in photocatalysis. Appl. Catal. Environ. 2015, 174, 367-375. [CrossRef]

42. Valenti, M.; Dolat, D.; Biskos, G.; Schmidt-Ott, A.; Smith, W.A. Enhancement of the photoelectrochemical performance of $\mathrm{CuWO}_{4}$ thin films for solar water splitting by plasmonic nanoparticle functionalization. J. Phys. Chem. 2015, 119, 2096-2104. [CrossRef]

43. Hou, W.; Liu, Z.; Pavaskar, P.; Hsuan Hung, W.; Cronin, S.B. Plasmonic enhancement of photocatalytic decomposition of methyl orange under visible light. J. Catal. 2011, 277, 149-153. [CrossRef]

44. Seh, Z.W.; Liu, S.W.; Low, M.; Zhang, S.-Y.; Liu, Z.; Mlayah, A.; Han, M.-Y. Janus Au-TiO 2 photocatalysts with strong localization of plasmonic near fields for efficient visible-light hydrogen generation. Adv. Mater. 2012, 24, 2310-2314. [CrossRef] [PubMed]

45. Chen, X.; Zhu, H.-Y.; Zhao, J.-C.; Zheng, Z.-F.; Gao, X.-P. Visible-light-driven oxidation of organic contaminants in air with gold nanoparticle catalysts on oxide supports. Angew. Chem. Int. Ed. 2008, 47, 5353-5356. [CrossRef] [PubMed]

46. Son, M.S.; Im, J.E.; Wang, K.K.; Oh, S.L.; Kim, Y.R.; Yoo, K.H. Surface plasmon enhanced photoconductance and single electron effects in mesoporous titania nanofibers loaded with gold nanoparticles. Appl. Phys. Lett. 2010, 96, 023115. [CrossRef]

47. Mukherjee, S.; Libisch, F.; Large, N.; Neumann, O.; Brown, L.V.; Cheng, J.; Lassiter, J.B.; Carter, E.A.; Nordlander, P.; Halas, N.J. Hot electrons do the impossible: Plasmon-induced dissociation of $\mathrm{H}_{2}$ on Au. Nano Lett. 2013, 13, 240-247. [CrossRef] [PubMed]

48. Kominami, H.; Tanaka, A.; Hashimoto, K. Gold nanoparticles supported on cerium(IV) oxide powder for mineralization of organic acids in aqueous suspensions under irradiation of visible light of $\lambda=530 \mathrm{~nm}$. Appl. Catal. Gen. 2011, 397, 121-126. [CrossRef]

49. Nishijima, Y.; Ueno, K.; Yokata, Y.; Murakoshi, K.; Misawa, H. Plasmon-assisted photocurrent generation from visible to near-infrared wavelength using a Au-nanorods $/ \mathrm{TiO}_{2}$ electrode. J. Phys. Chem. Lett. 2010, 1, 2031-2036. [CrossRef]

50. Kowalska, E.; Mahaney, O.O.P.; Abe, R.; Ohtani, B. Visible-light-induced photocatalysis through surface plasmon excitation of gold on titania surfaces. Phys. Chem. Chem. Phys. 2010, 12, 2344-2355. [CrossRef]

51. Bian, Z.F.; Tachikawa, T.; Zhang, P.; Fujitsuka, M.; Majima, T. Au/TiO ${ }_{2}$ superstructure-based plasmonic photocatalysts exhibiting efficient charge separation and unprecedented activity. J. Am. Chem. Soc. 2014, 136, 458-465. [CrossRef]

52. Murakami, N.; Kurihara, Y.; Tsubota, T.; Ohno, T. Shape-controlled anatase titanium(IV) oxide particles prepared by hydrothermal treatment of peroxo titanic acid in the presence of polyvinyl alcohol. J. Phys. Chem. 2009, 113, 3062-3069. [CrossRef]

53. Wei, Z.; Janczarek, M.; Endo, M.; Wang, K.L.; Balcytis, A.; Nitta, A.; Mendez-Medrano, M.G.; Colbeau-Justin, C.; Juodkazis, S.; Ohtani, B.; et al. Noble metal-modified faceted anatase titania photocatalysts: Octahedron versus decahedron. Appl. Catal. Environ. 2018, 237, 574-587. [CrossRef]

54. Wei, Z.; Kowalska, E.; Verrett, J.; Colbeau-Justin, C.; Remita, H.; Ohtani, B. Morphology-dependent photocatalytic activity of octahedral anatase particles prepared by ultrasonication-hydrothermal reaction of titanates. Nanoscale 2015, 7, 12392-12404. [CrossRef] [PubMed]

55. Leong, K.H.; Chu, H.Y.; Ibrahim, S.; Saravanan, P. Palladium nanoparticles anchored to anatase $\mathrm{TiO}_{2}$ for enhanced surface plasmon resonance-stimulated, visible-light-driven photocatalytic activity. Beilstein J. Nanotechnol. 2015, 6, 428-437. [CrossRef] [PubMed]

56. Zielinska-Jurek, A.; Wei, Z.; Wysocka, I.; Szweda, P.; Kowalska, E. The effect of nanoparticles size on photocatalytic and antimicrobial properties of $\mathrm{Ag}-\mathrm{Pt} / \mathrm{TiO}_{2}$ photocatalysts. Appl. Surf. Sci. 2015, 353, 317-325. [CrossRef]

57. DeSario, P.A.; Pietron, J.J.; Brintlinger, T.H.; McEntee, M.; Parker, J.F.; Baturina, O.; Stroud, R.M.; Rolison, D.R. Oxidation-stable plasmonic copper nanoparticles in photocatalytic $\mathrm{TiO}_{2}$ nanoarchitectures. Nanoscale 2017, 9 , 11720-11729. [CrossRef]

58. Link, S.; El-Sayed, M.A. Spectral properties and relaxation dynamics of surface plasmon electronic oscillations in gold and silver nanodots and nanorods. J. Phys. Chem. B 1999, 103, 8410-8426. [CrossRef]

59. Muniz-Miranda, M.; Gellini, C.; Simonelli, A.; Tiberi, M.; Giammanco, F.; Giorgetti, E. Characterization of Copper nanoparticles obtained by laser ablation in liquids. Appl. Phys. Mater. 2013, 110, 829-833. [CrossRef] 
60. Nilius, N.; Ernst, N.; Freund, H. On energy transfer processes at cluster-oxide interfaces: Silver on titania. Chem. Phys. Lett. 2001, 349, 351-357. [CrossRef]

61. Xia, Y.N.; Xiong, Y.J.; Lim, B.; Skrabalak, S.E. Shape-controlled synthesis of metal nanocrystals: Simple chemistry meets complex physics? Angew. Chem. Int. Ed. 2009, 48, 60-103. [CrossRef]

62. Yablonovitch, E. Photonic band-gap structures. J. Opt. Soc. Am. 1993, 10, 283-295. [CrossRef]

63. Lopez, C. Materials aspects of photonic crystals. Adv. Mater. 2003, 15, 1679-1704. [CrossRef]

64. Kim, W.T.; Choi, W.Y. Fabrication of $\mathrm{TiO}_{2}$ photonic crystal by anodic oxidation and their optical sensing properties. Sens. Actuators A Phys. 2017, 260, 178-184. [CrossRef]

65. Chiarello, G.L.; Zuliani, A.; Ceresoli, D.; Martinazzo, R.; Selli, E. Exploiting the photonic crystal properties of $\mathrm{TiO}_{2}$ nanotube arrays to enhance photocatalytic hydrogen production. ACS Catal. 2016, 6, 1345-1353. [CrossRef]

66. Zhang, Z.H.; Yang, X.L.; Hedhili, M.N.; Ahmed, E.; Shi, L.; Wang, P. Microwave-assisted self-doping of $\mathrm{TiO}_{2}$ photonic crystals for efficient photoelectrochemical water splitting. ACS Appl. Mater. Interfaces 2014, 6, 691-696. [CrossRef] [PubMed]

67. Zhang, Z.H.; Wu, H.J. Multiple band light trapping in ultraviolet, visible and near infrared regions with $\mathrm{TiO}_{2}$ based photonic materials. Chem. Commun. 2014, 50, 14179-14182. [CrossRef] [PubMed]

68. Li, Z.Z.; Xin, Y.M.; Wu, W.L.; Fu, B.H.; Zhang, Z.H. Phosphorus cation doping: A new strategy for boosting photoelectrochemical performance on $\mathrm{TiO}_{2}$ nanotube photonic crystals. ACS Appl. Mater. Interfaces 2016, 8, 30972-30979. [CrossRef]

69. Likodimos, V. Photonic crystal-assisted visible light activated $\mathrm{TiO}_{2}$ photocatalysis. Appl. Catal. Environ. 2018, 230, 269-303. [CrossRef]

70. Li, X.; Yu, J.G.; Jaroniec, M. Hierarchical photocatalysts. Chem. Soc. Rev. 2016, 45, 2603-2636. [CrossRef]

71. Chiang, C.C.; Tuyen, L.D.; Ren, C.R.; Chau, L.K.; Wu, C.Y.; Huang, P.J.; Hsu, C.C. Fabrication of titania inverse opals by multi-cycle dip-infiltration for optical sensing. Photonics Nanostruct. 2016, 19, 48-54. [CrossRef]

72. Lu, X.Y.; Zhu, Y.; Cen, T.Z.; Jiang, L. Centimeter-scale colloidal crystal belts via robust self-assembly strategy. Langmuir 2012, 28, 9341-9346. [CrossRef]

73. Jiang, P.; Bertone, J.F.; Hwang, K.S.; Colvin, V.L. Single-crystal colloidal multilayers of controlled thickness. Chem. Mater. 1999, 11, 2132-2140. [CrossRef]

74. Li, H.; Vienneau, G.; Jones, M.; Subramanian, B.; Robichaud, J.; Djaoued, Y. Crack-free 2D-inverse opal anatase $\mathrm{TiO}_{2}$ films on rigid and flexible transparent conducting substrates: Low temperature large area fabrication and electrochromic properties. J. Mater. Chem. 2014, 2, 7804-7810. [CrossRef]

75. Mayoral, R.; Requena, J.; Moya, J.S.; Lopez, C.; Cintas, A.; Miguez, H.; Meseguer, F.; Vazquez, L.; Holgado, M.; Blanco, A. 3D long-range ordering in an $\mathrm{SiO}_{2}$ submicrometer-sphere sintered superstructure. Adv. Mater. 1997, 9, 257-260. [CrossRef]

76. Kubrin, R.; Pasquarelli, R.M.; Waleczek, M.; Lee, H.S.; Zierold, R.; do Rosario, J.J.; Dyachenko, P.N.; Moreno, J.M.M.; Petrov, A.Y.; Janssen, R.; et al. Bottom-up fabrication of multilayer stacks of 3D photonic crystals from titanium dioxide. ACS Appl. Mater. Interfaces 2016, 8, 10466-10476. [CrossRef] [PubMed]

77. Curti, M.; Robledo, G.L.; Claro, P.C.D.; Ubogui, J.H.; Mendive, C.B. Characterization of titania inverse opals prepared by two distinct infiltration approaches. Mater. Res. Bull. 2018, 101, 12-19. [CrossRef]

78. Zhang, Y.; Li, K.; Su, F.Y.; Cai, Z.Y.; Liu, J.X.; Wu, X.W.; He, H.L.; Yin, Z.; Wang, L.H.; Wang, B.; et al. Electrically switchable photonic crystals based on liquid-crystal-infiltrated $\mathrm{TiO}_{2}$-inverse opals. Opt. Express 2019, 27, 15391-15398. [CrossRef]

79. Kim, K.; Thiyagarajan, P.; Ahn, H.J.; Kim, S.I.; Jang, J.H. Optimization for visible light photocatalytic water splitting: Gold-coated and surface-textured $\mathrm{TiO}_{2}$ inverse opal nano-networks. Nanoscale 2013, 5, 6254-6260. [CrossRef]

80. Zhou, Q.; Dong, P.; Liu, L.X.; Cheng, B.Y. Study on the sedimentation self-assembly of colloidal $\mathrm{SiO}_{2}$ particles under gravitational field. Colloids Surf. 2005, 253, 169-174. [CrossRef]

81. Hua, C.X.; Xu, H.B.; Zhang, P.P.; Chen, X.Y.; Lu, Y.Y.; Gan, Y.; Zhao, J.P.; Li, Y. Process optimization and optical properties of colloidal self-assembly via refrigerated centrifugation. Colloid. Polym. Sci. 2017, 295, 1655-1662. [CrossRef]

82. Miguez, H.; Meseguer, F.; Lopez, C.; Blanco, A.; Moya, J.S.; Requena, J.; Mifsud, A.; Fornes, V. Control of the photonic crystal properties of fcc-packed submicrometer $\mathrm{SiO}_{2}$ spheres by sintering. Adv. Mater. 1998, 10, 480-483. [CrossRef] 
83. Jovic, V.; Idriss, H.; Waterhouse, G.I.N. Slow photon amplification of gas-phase ethanol photo-oxidation in titania inverse opal photonic crystals. Chem. Phys. 2016, 479, 109-121. [CrossRef]

84. Cheng, C.W.; Karuturi, S.K.; Liu, L.J.; Liu, J.P.; Li, H.X.; Su, L.T.; Tok, A.I.Y.; Fan, H.J. Quantum-dot-sensitized $\mathrm{TiO}_{2}$ inverse opals for photoelectrochemical hydrogen generation. Small 2012, 8, 37-42. [CrossRef] [PubMed]

85. Liu, L.J.; Karuturi, S.K.; Su, L.T.; Tok, A.I.Y. $\mathrm{TiO}_{2}$ inverse-opal electrode fabricated by atomic layer deposition for dye-sensitized solar cell applications. Energy Environ. Sci. 2011, 4, 209-215. [CrossRef]

86. Li, X.H.; Wu, Y.; Shen, Y.H.; Sun, Y.; Yang, Y.; Xie, A.J. A novel bifunctional Ni-doped TiO 2 inverse opal with enhanced SERS performance and excellent photocatalytic activity. Appl. Surf. Sci. 2018, 427, 739-744. [CrossRef]

87. Moon, J.H.; Cho, Y.S.; Yang, S.M. Room temperature chemical vapor deposition for fabrication of titania inverse opals: Fabrication, morphology analysis and optical characterization. Korean Chem. Soc. 2009, 30, 2245-2248.

88. Curti, M.; Mendive, C.B.; Grela, M.A.; Bahnemann, D.W. Stopband tuning of $\mathrm{TiO}_{2}$ inverse opals for slow photon absorption. Mater. Res. Bull. 2017, 91, 155-165. [CrossRef]

89. Sordello, F.; Duca, C.; Maurino, V.; Minero, C. Photocatalytic metamaterials: $\mathrm{TiO}_{2}$ inverse opals. Chem. Commun. 2011, 47, 6147-6149. [CrossRef] [PubMed]

90. Wu, M.; Liu, J.; Jin, J.; Wang, C.; Huang, S.Z.; Deng, Z.; Li, Y.; Su, B.L. Probing significant light absorption enhancement of titania inverse opal films for highly exalted photocatalytic degradation of dye pollutants. Appl. Catal. Environ. 2014, 150, 411-420. [CrossRef]

91. Lu, Y.; Yu, H.T.; Chen, S.; Quan, X.; Zhao, H.M. Integrating plasmonic nanoparticles with $\mathrm{TiO}_{2}$ photonic crystal for enhancement of visible-light-driven photocatalysis. Environ. Sci. Technol. 2012, 46, 1724-1730. [CrossRef]

92. Curti, M.; Zvitco, G.; Grela, M.A.; Mendive, C.B. Angle dependence in slow photon photocatalysis using $\mathrm{TiO}_{2}$ inverse opals. Chem. Phys. 2018, 502, 33-38. [CrossRef]

93. Zhao, Y.X.; Yang, B.F.; Xu, J.; Fu, Z.P.; Wu, M.; Li, F. Facile synthesis of Ag nanoparticles supported on $\mathrm{TiO}_{2}$ inverse opal with enhanced visible-light photocatalytic activity. Thin Solid Films 2012, 520, 3515-3522. [CrossRef]

94. Srinivasan, M.; White, T. Degradation of methylene blue by three-dimensionally ordered macroporous titania. Environ. Sci. Technol. 2007, 41, 4405-4409. [CrossRef] [PubMed]

95. Wan, Y.; Wang, J.; Wang, X.; Xu, H.; Yuan, S.; Zhang, Q.; Zhang, M. Preparation of inverse opal titanium dioxide for photocatalytic performance research. Opt. Mater. 2019, 96, 109287. [CrossRef]

96. Rahul, T.K.; Sandhyarani, N. Nitrogen-fluorine co-doped titania inverse opals for enhanced solar light driven photocatalysis. Nanoscale 2015, 7, 18259-18270. [CrossRef]

97. Cai, J.M.; Wu, M.Q.; Wang, Y.T.; Zhang, H.; Meng, M.; Tian, Y.; Li, X.G.; Zhang, J.; Zheng, L.R.; Gong, J.L. Synergetic enhancement of light harvesting and charge separation over surface-disorder-engineered $\mathrm{TiO}_{2}$ photonic crystals. Chem 2017, 2, 877-892. [CrossRef]

98. Toumazatou, A.; Arfanis, M.K.; Pantazopoulos, P.-A.; Kontos, A.G.; Falaras, P.; Stefanou, N.; Likodimos, V. Slow-photon enhancement of dye sensitized $\mathrm{TiO}_{2}$ photocatalysis. Mater. Lett. 2017, 197, 123-126. [CrossRef]

99. Chen, Z.; Fang, L.; Dong, W.; Zheng, F.; Shen, M.; Wang, J. Inverse opal structured Ag/TiO 2 plasmonic photocatalyst prepared by pulsed current deposition and its enhanced visible light photocatalytic activity. J. Mater. Chem. 2014, 2, 824-832. [CrossRef]

100. Lim, S.Y.; Law, C.S.; Liu, L.; Markovis, M.; Abell, A.D.; Santos, A. Integrating surface plasmon resonance and slow photon effects in nanoporous anodis alumina photonic crystals for photocatalysis. Catal. Sci. Technol. 2019, 9, 3158-3176. [CrossRef]

101. Ye, J.; He, J.H.; Wang, S.; Zhou, X.J.; Zhang, Y.; Liu, G.; Yang, Y.F. Nickel-loaded black $\mathrm{TiO}_{2}$ with inverse opal structure for photocatalytic reduction of $\mathrm{CO}_{2}$ under visible light. Sep. Purif. Technol. 2019, 220, 8-15. [CrossRef]

102. Wang, X.Y.; Li, J.; Gao, X.N.; Shen, Y.H.; Xie, A.J. Ordered CdSe-sensitized $\mathrm{TiO}_{2}$ inverse opal film as multifunctional surface-enhanced Raman scattering substrate. Appl. Surf. Sci. 2019, 463, 357-362. [CrossRef]

103. Zheng, X.Z.; Li, D.Z.; Li, X.F.; Chen, J.; Cao, C.S.; Fang, J.L.; Wang, J.B.; He, Y.H.; Zheng, Y. Construction of $\mathrm{ZnO} / \mathrm{TiO}_{2}$ photonic crystal heterostructures for enhanced photocatalytic properties. Appl. Catal. Environ. 2015, 168, 408-415. [CrossRef] 
104. Lee, H.; Jeon, T.Y.; Lee, S.Y.; Lee, S.Y.; Kim, S.H. Designing multicolor micropatterns of inverse opals with photonic bandgap and surface plasmon resonance. Adv. Funct. Mater. 2018, 28, 1706664. [CrossRef]

105. Zhang, X.Y.; Zheng, Y.H.; Liu, X.; Lu, W.; Dai, J.Y.; Lei, D.Y.; MacFarlane, D.R. Hierarchical porous plasmonic metamaterials for reproducible ultrasensitive surface-enhanced Raman spectroscopy. Adv. Mater. 2015, 27, 1090-1096. [CrossRef] [PubMed]

106. Rahul, T.K.; Sandhyarani, N. Plasmonic and photonic effects on hydrogen evolution over chemically modified titania inverse opals. Chemnanomat 2018, 4, 642-648. [CrossRef]

107. Jiao, J.Q.; Wei, Y.C.; Chi, K.B.; Zhao, Z.; Duan, A.J.; Liu, J.; Jiang, G.Y.; Wang, Y.J.; Wang, X.L.; Han, C.C.; et al. Platinum nanoparticles supported on $\mathrm{TiO}_{2}$ photonic crystals as highly active photocatalyst for the reduction of $\mathrm{CO}_{2}$ in the presence of water. Energy Technol. 2017, 5, 877-883. [CrossRef]

108. Ding, B.Y.; Pemble, M.E.; Korovin, A.V.; Peschel, U.; Romanov, S.G. Three-dimensional photonic crystals with an active surface: Gold film terminated opals. Phys. Rev. 2010, 82, 035119. [CrossRef]

109. Paterno, G.M.; Moscardi, L.; Donini, S.; Ariodanti, D.; Kriegel, I.; Zani, M.; Parisini, E.; Scotognella, F.; Lanzani, G. Hybrid one-dimensional plasmonic-photonic crystals for optical detection of bacterial contaminants. J. Phys. Chem. Lett. 2019, 10, 4980-4986. [CrossRef]

110. Zhao, H.; Hu, Z.Y.; Liu, J.; Li, Y.; Wu, M.; Van Tendeloo, G.; Su, B.L. Blue-edge slow photons promoting visible-light hydrogen production on gradient ternary $3 \mathrm{DOM} \mathrm{TiO} 2-\mathrm{Au}-\mathrm{CdS}$ photonic crystals. Nano Energy 2018, 47, 266-274. [CrossRef]

111. Erola, M.O.A.; Philip, A.; Ahmed, T.; Suvanto, S.; Pakkanen, T.T. Fabrication of Au- and Ag-SiO ${ }_{2}$ inverse opals having both localized surface plasmon resonance and Bragg diffraction. J. Solid State Chem. 2015, 230, 209-217. [CrossRef]

112. Chen, J.I.L.; Loso, E.; Ebrahim, N.; Ozin, G.A. Synergy of slow photon and chemically amplified photochemistry in platinum nanocluster-loaded inverse titania opals. J. Am. Chem. Soc. 2008, 130, 5420-5421. [CrossRef]

113. Sanchez-Garcia, L.; Tserkezis, C.; Ramirez, M.O.; Molina, P.; Carvajal, J.J.; Aguilo, M.; Diaz, F.; Aizpurua, J.; Bausa, L.E. Plasmonic enhancement of second harmonic generation from nonlinear $\mathrm{RbTiOPO}_{4}$ crystals by aggregates of silver nanostructures. Opt. Express 2016, 24, 8491-8500. [CrossRef]

114. Meng, S.G.; Li, D.Z.; Fu, X.L.; Fu, X.Z. Integrating photonic bandgaps with surface plasmon resonance for the enhancement of visible-light photocatalytic performance. J. Mater. Chem. 2015, 3, 23501-23511. [CrossRef]

115. Zeng, S.; Vahidzadeh, E.; VanEssen, C.G.; Kar, P.; Kisslinger, R.; Goswami, A.; Zhang, Y.; Mandi, N.; Riddell, S.; Kobryn, A.E.; et al. Optical control of selectivity of high rate $\mathrm{CO}_{2}$ photoreduction via interbandor hot electron Z-scheme reaction pathways in $\mathrm{Au}-\mathrm{TiO}_{2}$ plasmonic photonic crystal photocatalyst. Appl. Catal. Environ. 2020, 267, 118644. [CrossRef]

116. Fang, L.; Nan, F.; Yang, Y.; Cao, D.W. Enhanced photoelectrochemical and photocatalytic activity in visible-light-driven $\mathrm{Ag} / \mathrm{BiVO}_{4}$ inverse opals. Appl. Phys. Lett. 2016, 108, 093902. [CrossRef]

117. Zhang, Z.; Zhang, L.; Hedhili, M.N.; Zhang, H.; Wang, P. Plasmonic gold nanocrystals coupled with photonic crystal seamlessly on $\mathrm{TiO}_{2}$ nanotube photoelectrodes for efficient visible light photoelectrochemical water splitting. Nano Lett. 2013, 13, 14-20. [CrossRef] [PubMed]

118. Zhang, X.; Liu, Y.; Lee, S.T.; Yang, S.H.; Kang, Z.H. Coupling surface plasmon resonance of gold nanoparticles with slow-photon-effect of $\mathrm{TiO}_{2}$ photonic crystals for synergistically enhanced photoelectrochemical water splitting. Energy Environ. Sci. 2014, 7, 1409-1419. [CrossRef]

119. Wang, Y.F.; Xiong, D.B.; Zhang, W.; Su, H.L.; Liu, Q.L.; Gu, J.J.; Zhu, S.M.; Zhang, D. Surface plasmon resonance of gold nanocrystals coupled with slow-photon-effect of biomorphic $\mathrm{TiO}_{2}$ photonic crystals for enhanced photocatalysis under visible-light. Catal. Today 2016, 274, 15-21. [CrossRef]

120. Huo, J.W.; Yuan, C.; Wang, Y. Nanocomposites of three-dimensionally ordered porous $\mathrm{TiO}_{2}$ decorated with $\mathrm{Pt}$ and reduced graphene oxide for the visible-light photocatalytic degradation of waterborne pollutants. ACS Appl. Nano Mater. 2019, 2, 2713-2724. [CrossRef]

121. Temerov, F.; Ankudze, B.; Saarinen, J.J. $\mathrm{TiO}_{2}$ inverse opal structures with facile decoration of precious metal nanoparticles for enhanced photocatalytic activity. Mater. Chem. Phys. 2020, 242, 122471. [CrossRef]

122. Zhang, S.S.; Peng, B.Y.; Yang, S.Y.; Wang, H.G.; Yu, H.; Fang, Y.P.; Peng, F. Non-noble metal copper nanoparticles-decorated $\mathrm{TiO}_{2}$ nanotube arrays with plasmon-enhanced photocatalytic hydrogen evolution under visible light. Int. J. Hydrog. Energy 2015, 40, 303-310. [CrossRef]

123. Zhang, L.W.; Lin, C.Y.; Valev, V.K.; Reisner, E.; Steiner, U.; Baumberg, J.J. Plasmonic enhancement in $\mathrm{BiVO}_{4}$ photonic crystals for efficient water splitting. Small 2014, 10, 3970-3978. [CrossRef] 
124. Dinh, C.T.; Yen, H.; Kleitz, F.; Do, T.O. Three-dimensional ordered assembly of thin-shell Au/TiO 2 hollow nanospheres for enhanced visible-light-driven photocatalysis. Angew. Chem. Int. Ed. 2014, 53, 6618-6623. [CrossRef] [PubMed]

125. Alessandri, I.; Ferroni, M. Exploiting optothermal conversion for nanofabrication: Site-selective generation of $\mathrm{Au} / \mathrm{TiO}_{2}$ inverse opals. J. Mater. Chem. 2009, 19, 7990-7994. [CrossRef]

126. Wei, Z.; Endo, M.; Wang, K.; Charbit, E.; Markowska-Szczupak, A.; Ohtani, B.; Kowalska, E. Noble metal-modified octahedral anatase titania particles with enhanced activity for decomposition of chemical and microbiological pollutants. Chem. Eng. J. 2017, 318, 121-134. [CrossRef] [PubMed]

127. Raja-Mogan, T.; Lehoux, A.; Takashima, M.; Kowalska, E.; Ohtani, B. A triply wavelength-tuned visible light-responsive photocatalyst: Matching of LED, PBG and LSPR. 2020. under preparation for submission.

C 2020 by the authors. Licensee MDPI, Basel, Switzerland. This article is an open access article distributed under the terms and conditions of the Creative Commons Attribution (CC BY) license (http://creativecommons.org/licenses/by/4.0/). 